Original Articles

\title{
The grammar of anger: Mapping the computational architecture of a recalibrational emotion
}

\author{
Aaron Sell a,b,*, Daniel Sznycer ${ }^{\mathrm{a}, \mathrm{c}, \mathrm{i}}$, Laith Al-Shawaf ${ }^{\mathrm{d}, \mathrm{e}}$, Julian Lim ${ }^{\mathrm{a}}$, Andre Krauss $^{\mathrm{f}}$, Aneta Feldman ${ }^{\mathrm{g}}$, \\ Ruxandra Rascanu $^{\mathrm{g}}$, Lawrence Sugiyama ${ }^{\mathrm{h}}$, Leda Cosmides ${ }^{\mathrm{a}}$, John Tooby ${ }^{\mathrm{a}}$ \\ ${ }^{a}$ Center for Evolutionary Psychology, University of California, Santa Barbara, CA 93106, USA \\ ${ }^{\mathrm{b}}$ School of Criminology and Criminal Justice, Griffith University, Mount Gravatt, QLD 4111, Australia \\ ${ }^{\mathrm{c}}$ Department of Psychology, Arizona State University, Tempe, AZ 85287-1104, USA \\ ${ }^{\mathrm{d}}$ Department of Psychology and Interdisciplinary Neuroscience Program, Bilkent University, 06800 Bilkent, Ankara, Turkey \\ e College of Life Sciences, Institute for Advanced Study, Berlin, Germany \\ ${ }^{\mathrm{f}}$ Center for the Study of Entertainment Media Influences, Arad 310130, Romania \\ ${ }^{\mathrm{g}}$ Department of Psychology, The University of Bucharest, București 030018, Romania \\ ${ }^{\mathrm{h}}$ Department of Anthropology and Institute of Cognitive and Decision Sciences, University of Oregon, Eugene, OR 97403, USA \\ ${ }^{i}$ Université de Montréal, Département de Psychologie, Pavillon Marie Victorin, C.P. 6128, succursale Centre-ville, Montréal, QC H3C 3J7, Canada
}

\section{A R T I C L E I N F O}

\section{Article history:}

Received 14 November 2016

Revised 30 May 2017

Accepted 3 June 2017

Available online 29 June 2017

\section{Keywords:}

Anger

Evolutionary psychology

Arguments

Welfare tradeoff ratio

Recalibrational theory

\begin{abstract}
A B S T R A C T
According to the recalibrational theory of anger, anger is a computationally complex cognitive system that evolved to bargain for better treatment. Anger coordinates facial expressions, vocal changes, verbal arguments, the withholding of benefits, the deployment of aggression, and a suite of other cognitive and physiological variables in the service of leveraging bargaining position into better outcomes. The prototypical trigger of anger is an indication that the offender places too little weight on the angry individual's welfare when making decisions, i.e. the offender has too low a welfare tradeoff ratio (WTR) toward the angry individual. Twenty-three experiments in six cultures, including a group of foragers in the Ecuadorian Amazon, tested six predictions about the computational structure of anger derived from the recalibrational theory. Subjects judged that anger would intensify when: (i) the cost was large, (ii) the benefit the offender received from imposing the cost was small, or (iii) the offender imposed the cost despite knowing that the angered individual was the person to be harmed. Additionally, anger-based arguments conformed to a conceptual grammar of anger, such that offenders were inclined to argue that they held a high WTR toward the victim, e.g., "the cost I imposed on you was small", "the benefit I gained was large", or "I didn't know it was you I was harming." These results replicated across all six tested cultures: the US, Australia, Turkey, Romania, India, and Shuar hunter-horticulturalists in Ecuador. Results contradict key predictions about anger based on equity theory and social constructivism.
\end{abstract}

(c) 2017 Elsevier B.V. All rights reserved.

\section{Introduction}

Anger is a complex neural system that orchestrates behavior, physiology, facial and vocal expressions, perceptual changes, motivational priorities, memory, attention, and energy regulation in response to interpretations of social events (Fessler, 2010; Lazarus, 1991; Potegal, Stemmler, \& Spielberger, 2010; Sell, 2011a; Smith \& Ellsworth, 1985; Tooby \& Cosmides, 1990). This system is instantiated in a network of brain regions (Kragel \& LaBar, 2016), shows early ontogenetic development (e.g. the anger

\footnotetext{
* Corresponding author at: School of Criminology and Criminal Justice, Griffith University, Mount Gravatt Campus, Mount Gravatt, QLD 4111, Australia.

E-mail address: a.sell@griffith.edu.au (A. Sell).
}

face is functional at six months; Stenberg, Campos, \& Emde, 1983), and demonstrates cross-cultural uniformity in basic design (Alonso-Arbiol et al., 2011; Ekman, 1973; Wallbott \& Scherer, 1986). Furthermore, some features of anger are known to develop without exposure to the information that would be required to learn them through more general purpose systems, e.g., congenitally blind children produce normal anger facial expressions (Galati, Sini, Schmidt, \& Tinti, 2003). This evidence fits with the generally accepted conclusion that anger is - at least in part - a species-typical system designed by natural selection (Potegal et al., 2010; though see Barrett, 2017).

If anger did indeed evolve by natural selection, then identifying the function of anger (i.e., the way in which it increased the fitness of our ancestors) should predict and explain the 
information-processing structure of anger, just as understanding the function of mate choice has allowed evolutionary psychologists to explain the complexly organized nature of attractiveness (e.g. Sugiyama, 2005).

The recalibrational theory holds that anger evolved to bargain for better treatment. This theory was first derived from basic principles of evolutionary biology, including the theory of bargaining and game theory (Sell, 2006; Sell, Tooby, \& Cosmides, 2009), which argue that organisms have two fundamental tools to bargain for better outcomes: conditional aggression (threat), or conditional cooperation (contingent benefit delivery). With these, organisms can incentivize the other party to shift their behavior in a way that is favorable to the bargainer. This underlying theoretical approach to bargaining was combined with a leading evolutionary approach to emotions, which holds that the neural basis of any specific emotion is conceptualized as a superordinate control program that evolved to orchestrate the diverse mechanisms in the organism into a best-bet configuration to respond to an evolutionarily recurrent adaptive problem (Sell et al., 2009; Tooby \& Cosmides, 1990, 2008).

The function identified by the recalibrational theory of anger is to resolve conflicts of interest more in favor of the angry individual. That is, the anger system was designed by natural selection to orchestrate the subcomponents of the organism's architecture (e.g. physiology, behavior, cognitive structures) in order to leverage its bargaining advantages over another organism and incentivize that organism to place more weight on the angry individual's welfare. Informally, the signal is (in cooperative relationships) do more of what I want or I will do less of what you want, and (in noncooperative relationships) do more of what I want or I will inflict costs on you.

Elsewhere we have more fully derived this adaptationist theory of the design of anger from basic principles (Sell, 2006; Sell et al., 2009; Tooby \& Cosmides, 2008). In this paper, we add to this by examining how some of the major features of anger support the hypothesis that they evolved in the service of bargaining for better treatment (Sections 1.1 and 1.2). We then use the theory to generate six hypotheses about the triggers of anger (Section 1.4), and experimentally test them with vignettes in six cultures. Predictions \#1 through \#3 relate to the computational structure of the triggers of anger; predictions \#4 through \#6 relate to how people argue over an incident of anger.

\subsection{The recalibrational theory as a guide to reverse engineering anger}

According to the recalibrational theory of anger (Sell, 2006, 2011a, 2011b; Sell et al., 2009; Tooby, Cosmides, Sell, Lieberman, \& Sznycer, 2008) anger is designed to bargain for better treatment. Thus, anger has features designed to gather the attention of the target and interact with that target in ways that - if successful - incline the target to behave in a way that more highly values the angry person's interests in the present or future. Indeed, the major features of anger are all consistent with this function (see also Sell, 2011a, 2011b; Sell et al., 2009):

\subsubsection{The major triggers of anger are cues of the target's motivational} state

The most common triggers of anger are cues about what might loosely be identified as the intentions and beliefs of the target of anger; and experiments reveal that it is these intentions and beliefs that trigger anger more than any particular tangible harm (Averill, 1982; Epstein \& Taylor, 1967; Ohbuchi \& Kambara, 1985; Smith \& Ellsworth, 1985). Furthermore, anger-based aggression typically results from the revelation that the target of anger does not "respect" the angry individual rather than any specific harm done (Daly \& Wilson, 1988; Felson, 1982). (Here, we interpret "respect" to mean the weight placed on the actor's welfare.) Finally, anger focuses attention on cues of the target's mental state which is often probed directly, i.e. the targets of anger are frequently interrogated about why they did what they did (Averill, 1982). In sum, anger is activated by cues of what the target thinks of the angry person and the importance of their affairs. These are indispensable design features we would expect in a system designed to recalibrate a target's propensity to place weight on the actor's interests.

\subsubsection{Anger is designed to gather the target's attention}

An adaptation designed to recalibrate a target's mind must seek out that target. Therefore, anger - particularly in the early stages of its deployment- motivates approach toward the target of anger (an anomaly among negatively valenced emotions; Carver \& Harmon-Jones, 2009). Furthermore, anger signals its onset to the target with a highly recognizable (Fox et al., 2000; Öhman, Lundqvist, \& Esteves, 2001) and universal facial expression (Ekman, 1973). According to the recalibrational theory, the anger expression is the signal that the target's action expresses too little weight-that is, is an unacceptably low "bid", and that this bid is rejected. Finally, during aggressive bargaining, the anger face triggers muscles in the face that enhance cues of physical strength and fighting ability (Sell, Cosmides, \& Tooby, 2014) in a way analogous to non-human animals that bare their fangs or inflate their lungs as threats to aggression.

\subsubsection{The most common response to anger is rapid information exchange}

Once anger has motivated the actor to gather the attention of the target, it enacts strategies designed to interface with and recalibrate cognitive structures in the target (Averill, 1982, 1983). This is usually done by rapid, focused communication with the target, e.g., an argument or a display. During these arguments, anger modifies the voice in ways that generally increase the speed and salience of speech (Banse \& Scherer, 1996), and signal through increasing volume and roughening of the voice the activation of the sympathetic pathways involved in preparation for combat. This communication should be relevant to the bargaining dynamics between the two individuals, based on the ability to confer benefits, or to inflict harms (aggression). The angry individual should emphasize that the offense placed too little weight on their welfare, given the benefit to the offender. Other relevant features are the importance of the benefits that the angry individual has conferred previously, or could withhold. If the two are not in a cooperative relationship, then the angry individual could emphasize his ability to inflict costs (demonstrate formidability) by e.g., pounding a table, shaking a fist, breaking something, or striking the target (see Section 4).

\subsubsection{Anger-based aggression is largely communicative}

Although anger usually does not lead to aggression (Averill, 1983), when it does, the design of this aggression is communicative in nature; in other words, the aggression does not efficiently injure or kill the target, but instead demonstrates fighting ability, determination, or the willingness to take the interaction into the realm of physical harm. An incident of anger-based aggression typically starts with aggressive signaling, will dissipate if the target retreats or submits, and escalates from less dangerous to more dangerous aggressive acts only if the target retaliates or fails to conciliate (Felson, 1982). Thus, anger-based aggression typically appears designed to recalibrate the target rather than incapacitate or kill. 


\subsubsection{Apologies typically extinguish anger}

If the function of anger is to bargain for better treatment by recalibrating the mind of the target, anger should be designed to turn off when this has been accomplished, just as hunger is switched off after feeding. Indeed, the best method of defusing an incidence of anger is to offer a sincere verbal indicator of internal recalibration (i.e. an apology, Frantz \& Bennigson, 2005; Ohbuchi, Kameda, \& Agarie, 1989). Apologies are effective even when the target offers no tangible recompense, indicating that the function of anger is not just to get immediate access to resources but rather to recalibrate the target's mind so that the future propensity of the target to take the angry individual's interests into account has reached an acceptable level.

Together, this evidence suggests that anger is a complex system that is triggered by implicit calculations about the contents of the target's mind typically revealed during a conflict. Anger opens a channel with the target by gathering their attention and then delivers (and receives) relevant information (verbal and otherwise) until the target has been recalibrated.

We can derive a more computationally-specific account of anger if we know exactly what computational structures in the target's mind are being recalibrated by anger. According to the recalibrational theory, anger primarily bargains by recalibrating a cognitive structure called the welfare tradeoff ratio (WTR) (Sell, 2006, 2011a, 2011b; Sell et al., 2009; Tooby et al., 2008). A welfare tradeoff ratio is, by hypothesis, an internal regulatory variable (Tooby et al., 2008) ${ }^{1}$ that governs how much an individual weights another's welfare against her own when making decisions. ${ }^{2}$ The higher one's WTR toward another individual, the more weight one puts on their welfare when making decisions. Because anger is primarily designed to recalibrate this variable, understanding the computational structure of the welfare tradeoff ratio will explain the features of anger in the same way that the structure of a lock explains the features of a key.

\subsection{The computational structure of the welfare tradeoff function}

Humans must make decisions that jointly impact the welfare (positively and negatively) of self and others. As with other animals, natural selection would be expected to shape adaptations that govern when an individual should sacrifice their own welfare to benefit another, and when they should sacrifice another's welfare to benefit themselves (Sell et al., 2009). Biologists have identified a number of different selection pressures that, when the right conditions are satisfied, favor an organism placing at least some weight on another's interests at the expense of their own (e.g. parenting, genetic kinship, future value in a cooperative relationship, threats of punishment or aggressive extortion, joint coalitional membership; for discussion see Tooby et al., 2008). Each of these may be thought of as evolutionarily repeated games, which have best bet strategies given the situation of the players. We expect these strategies will predict the motivational subsystems of

\footnotetext{
${ }^{1}$ Internal regulatory variables are structures in an organism that store information needed to effectively calibrate emotions and motivational systems so that they regulate the organism's behavior functionally. For example, an organism's detection of its blood sugar regulates feeding, and a kinship index tracks genetic relatedness and so generates sexual revulsion at close genetic relatives, and directs altruism toward them (Tooby et al., 2008). They do not correspond to beliefs and intentions as ordinarily construed.

2 Some prefer the term "welfare tradeoff parameterization" or WTP rather than "welfare tradeoff ratio" so as not to imply a constant ratio across all magnitudes of conflict; e.g. someone could weight their friend's welfare equal to their own when deciding who gets the closest parking space but not when deciding who gets the promotion.
}

humans when facing these situations. While these selection pressures are modeled one by one, real organisms may be faced with familiar social others with whom they are playing several games at once, and so these best-bet strategies must be integrated to decide how to partition decisions where the favored outcome is benefiting the other person (benefitdelivery) from decisions where the favored outcome is benefitting oneself ("selfish" action). This requires a neurocomputational program that integrates various relevant factors and generates output - for a given decision set- reflecting how much consideration an individual will place on the welfare of that other person. We call the function that does this inputoutput mapping the "welfare tradeoff function", and call its output the welfare tradeoff ratio (WTR) (Petersen, Sell, Tooby, \& Cosmides, 2010; Sell, 2006, 2011b; Sell et al., 2009; Tooby et al., 2008).

The welfare tradeoff ratio specifies the threshold for an acceptable cost-benefit transaction with another individual, such that for agent $\mathrm{X}$ with respect to $\mathrm{Y}, \mathrm{WTR}_{\mathrm{XY}}=$ benefit to $\mathrm{X} /$ cost to $Y$ for a specific range of conditions. The WTR $\mathrm{XY}_{\mathrm{X}}$ indicates the cost-benefit transaction below which $X$ will refrain from imposing the cost on $\mathrm{Y}$, but above which $\mathrm{X}$ will impose the cost on $\mathrm{Y}$; in colloquial terms, it represents how much X "cares" about Y's welfare when making decisions that impact them both. Thus, if agent $X$ held a WTR toward agent $Y$ of $1 / 2$, then $X$ would impose a cost of 2 on $Y$ in order to benefit 1 , but would not impose a cost of 9 in order to benefit 4. WTRs are personspecific, however, so that one will likely have high WTRs toward cooperative partners, close relatives, and powerful others, but low WTRs (or even negative WTRs) toward enemies, strangers, and competitors.

The evolved function of the welfare tradeoff ratio is to regulate cost/benefit transactions between the individual and specific others in ways that were, over evolutionary time, fitness promoting to the individual holding the WTR, e.g. to care sufficiently about one's friend but not to a self-destructive degree, to defer sufficiently but not excessively to a dominant group member, and so on. To do this, an individual's welfare tradeoff function would need to: (i) estimate variables that predicted the ancestral fitness consequences of helping or harming another under a given set of conditions and (ii) calibrate the WTR toward that person in response to those estimates in accordance with the best-bet strategies of the relevant evolutionary games or functions. For example, because of the genetics of sexual reproduction described by kin selection theory, individuals are adapted to deliver benefits to kin at a cost to themselves (Hamilton, 1964). Therefore, there must exist a system that perceives evolutionarily reliable, cues of kinship, (such as maternal-perinatal association and duration of childhood coresidency), and then upregulates the individual's WTR toward individuals the system has classified as close genetic relatives (Lieberman, Tooby, \& Cosmides, 2007; Sznycer, De Smet, Billingsley, \& Lieberman, 2016). This raised WTR causes the actor to place a greater weight on the welfare of their kin when making decisions about whether to help or harm them (see Madsen et al., 2007).

Here we focus on welfare tradeoffs that are hypothesized to be calibrated by bargaining power, e.g. the ability to costeffectively confer or withdraw benefits and impose costs. For example, models of animal conflict show that relative fighting ability (i.e., formidability) partly determines the costs of exploiting others and the costs of resisting exploitation from others (Alcock, 2005; Hammerstein \& Parker, 1982; Huntingford \& Turner, 1987; Maynard Smith \& Parker, 1976). Therefore, humans - and many other animals - evolved perceptual mechanisms designed to assess cues of formidability in the body, 
face, and voice (Sell et al., 2009, 2010), and respond to these cues by calibrating welfare tradeoff ratios such that males who are better fighters are expected - by themselves and others - to receive greater consideration (Delton \& Sell, 2014; Hess, Helfrecht, Hagen, Sell, \& Hewlett, 2010; Lukaszewski, 2013; Petersen, Sznycer, Sell, Cosmides, \& Tooby, 2013; Pietraszewski \& Shaw, 2015; Sell et al., 2009; Thomsen, Frankenhuis, Ingold-Smith, \& Carey, 2011). Similar cue-based computational systems underlie reciprocity, prestige and deepengagement friendships that calibrate welfare tradeoff ratios to the ecology of human cooperation (Delton \& Robertson, 2016; Kirkpatrick, Delton, Robertson, \& de Wit, 2015; Komorita, Parks, \& Hulbert, 1992; Petersen, Sell, Tooby, \& Cosmides, 2012; Sell et al., 2009; Sznycer et al., 2012; Tooby \& Cosmides, 1996).

In conclusion, an individual will have different welfare tradeoff ratios for different individuals, such that more formidable people, relatives, reciprocity partners, and those with high cooperative value will have their welfare valued more highly - all else equal. Welfare tradeoff ratios thus underlie folk notions of respect, deference, dominance, love, and friendship, but are derived from evolutionary theory and formalized so as to allow for more precise computational predictions that do not rely on intuition or folk psychology. With this understanding of the computational nature of the welfare tradeoff system, we can make more specific predictions about how anger functions to recalibrate WTRs.

\subsection{Welfare tradeoff ratios and the recalibrational theory of anger}

The recalibrational theory holds that anger is a neurocognitive system that evolved primarily to bargain for better treatment from those who reveal in their behavior that their welfare tradeoff ratios toward the offended individual are lower than they "ought" to be given the history of the negotiated relationship and the relative power of the interactants (Sell, 2011b; Sell et al., 2009). Thus, anger is triggered when it detects that the other party is not placing sufficient weight on the welfare of the actor. More specifically, the anger system compares the target's apparent WTR - estimated from behavioral cues - (i.e., the observed WTR) to the WTR that the angry person feels entitled to from that person (i.e., expected WTR). If the observed WTR is lower than the expected WTR, anger is triggered.

Once activated, the anger program opens a channel for communication with the target, and feeds information to the target's WTR-setting cognitive system. Because WTRs are calibrated by estimates of bargaining power such as physical formidability, ability to confer benefits, cooperative reliability, coalitional support, and so on (Lukaszewski, 2013; Sell, Eisner, \& Ribeaud, 2016; Sell et al., 2009; Tooby et al., 2008), anger can recalibrate the target's WTR by demonstrating the willingness and ability of the angry person to inflict costs (i.e., aggression) or withhold or curtail benefits (Sell, 2011b; Sell et al., 2009; Williams, Shore, \& Grahe, 1998). This is why anger-based aggression is communicative in nature (see Section 1.1.4). These strategies are designed to recalibrate the WTR of the target by showing them that they will be worse off - in the long run - by continuing to behave in ways that place too little weight on the angry person's welfare (for related arguments see Frank, 1988; Hirshleifer, 1984).

In conclusion, by identifying the aspects of natural selection that led to the evolution of the human anger system, the recalibrational theory enables the mapping of the computational structure of anger, including its input conditions. In short, it can explain how anger is triggered, which appraisals lead to anger, and why.

\subsection{Triggers of anger}

According to this theory, the primary activating conditions for anger will be cues that indicate another individual maintains a lower welfare tradeoff ratio than is acceptable given their negotiated relationship. These cues exist in many formats because the WTR is likely to be used by many different motivational, emotional, and cognitive mechanisms. That is, how much weight a person puts on another's welfare may leak through many channels. For example, the degree to which one values the welfare of another presumably regulates the fidelity of memory encoding such that information about an individual who is highly valued is more likely to be remembered. Thus, ignorance about a person can indicate a low WTR toward that person and activate anger in them. Similar indications of low WTRs can come from infrequent consideration of the individual's interests ("Why don't you ever ask what I want?"), a low evaluation of an individual on a trait that is relevant to the calibration of WTRs such as intelligence or physical formidability in men (Harris, 1993; Preston \& Kimberley, 1987), and a lack of empathic feelings, i.e. being uninterested in a person's pain or joy (Lanzetta \& Englis, 1989). That said, the most common trigger of anger is a cost imposition (Averill, 1982, 1983).

\subsubsection{Cost impositions as indicators of WTR}

When an individual imposes a cost on another in order to receive a benefit (hereafter termed a "cost-benefit transaction"), the imposer indicates the upper bound of their welfare tradeoff ratio toward the individual on whom the cost was imposed. Specifically, when actor $\mathrm{X}$ imposes a cost on $\mathrm{Y}$ in order to receive a benefit, the highest WTR X could have toward $Y$ (i.e. $W R_{X Y}$ ) is: (benefit to $\mathrm{X}) /($ cost to $\mathrm{Y}$ ). Thus, the upper bound of the WTR that $\mathrm{X}$ has toward $\mathrm{Y}$ becomes lower as the cost imposed on $\mathrm{Y}$ increases and the benefit $X$ receives as a result of that cost decreases. See Fig. 1. Put simply, an individual demonstrates that they value your welfare less when they are willing to impose large costs on you in order to benefit a small amount.

This leads to two predictions about how cost impositions trigger anger:

- Prediction \#1: Holding the benefit the offender received constant, anger will become more intense as the cost imposed on the angry person increases.

lower benefit to $\mathrm{X}=$ lower WTRxy

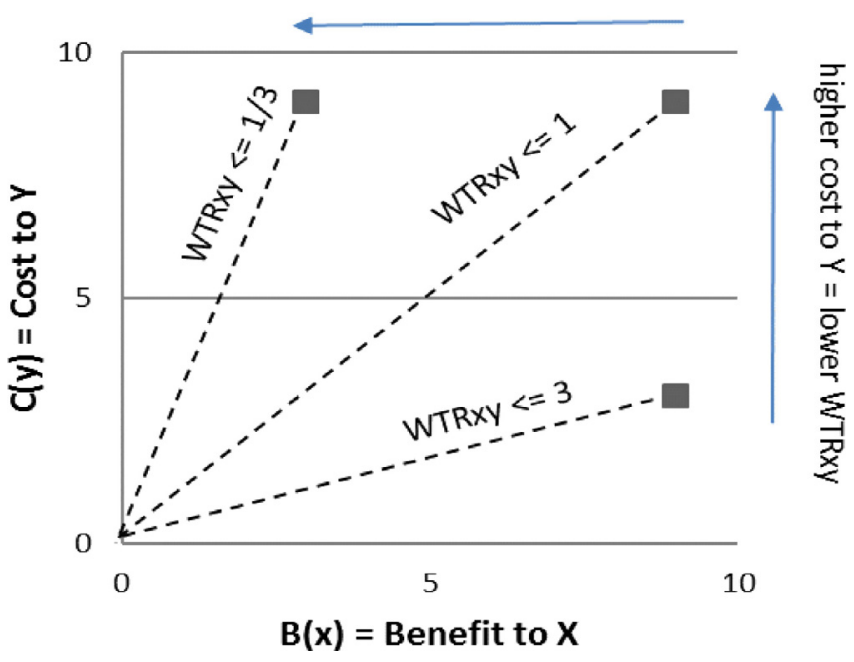

Fig. 1. A lower WTRxy is indicated as $C(y)$ increases and $B(x)$ decreases. 
- Prediction \#2: Holding the cost imposed constant, anger will become less intense as the benefit the target received increases.

Prediction \#1 has been demonstrated in the established literature across many types of costs; e.g., voltage of electric shocks (O'Leary and Dengerink, 1973), monetary costs (Fehr \& Gaechter, 2000). Prediction \#2, however, is not established and is directly contrary to the predictions of some theories of anger, such as equity theory (see Section 6). Experiment Set A was designed as a cross-cultural test of this prediction.

Furthermore, because welfare tradeoff ratios are personspecific, the imposition of a large cost for a small benefit will clearly indicate a low WTR toward an individual only if it was known by the actor that the cost would be imposed on that specific individual (see Section 3 for more details). This leads to another key prediction:

- Prediction \#3: Holding the costs and benefits constant, anger will be more intense when the offender deliberately imposes the cost on the angry individual as opposed to imposing the cost at random.

Experiment Set B was designed as a cross-cultural test of prediction \#3.

Finally, if these predictions hold, one would expect that targets of anger - when confronted by an angry individual - should use verbal statements that deactivate anger by negating these input conditions (see Section 4). In other words, targets of anger should argue that they hold a high WTR toward the angry individual. This means that during arguments, the offender should prefer to argue that:

- Prediction \#4: the cost the offender imposed was small.

- Prediction \#5: the benefit the offender received as a result of imposing the cost was large.

- Prediction \#6: the offender imposed the cost without knowing it would be inflicted on the target specifically.

These three predictions are tested across six cultures in Experiment Set C.

\section{Experiment Set A: What is the effect of the offender's benefit on anger?}

A vignette with a simple between-subjects experimental design was used in six populations (US, Australia, Romania, India, Turkey, and the Shuar of Ecuador) to test prediction \#2. In the vignette, a cost is imposed on the subject. The subject then learns why the cost was imposed. In the large benefit condition, the offender received a large benefit for imposing the cost; in the small benefit condition the offender gained only a small benefit. It is hypothe- sized that subjects will be more angry when they learn that they were harmed for a small benefit, as this indicates a lower welfare tradeoff ratio (prediction \#2).

\subsection{Method for Experiments A1-A5}

American Subjects (A1): One hundred and nine undergraduates (72 female) from the University of California, Santa Barbara (UCSB) participated in Experiment A1 for partial fulfillment of their introductory psychology course (mean age: 18.3 , SD: 0.72 , range: $17-$ 21).

Australian Subjects (A2): Three hundred and twenty-two undergraduates (239 female) from Griffith University participated in Experiment A2 for partial fulfillment of their psychology of crime course (mean age: 21.9, SD: 5.09, range: 17-52).

Romanian Subjects (A3): Three hundred and twenty-eight Romanian students (182 female) from the Universities of Arad, BabesBolyai, Bucharest, and Alexandru Ioan Cuza volunteered to participate in Experiment A3 (mean age: 21.0, SD: 2.5, range: 18-37). There was no monetary compensation.

Indian Subjects (A4): One hundred and fifty-five (49 female) residents of India responded to a survey on the online system Mechanical Turk (mTurk) in exchange for $\$ 0.50$ (USD) (mean age: 32.7, SD: 9.5, range: 20-71). A comprehension task was used to eliminate subjects who did not understand English or were not paying attention. Forty-nine subjects failed the comprehension task and were eliminated, leaving a final sample of 106 ( 26 female; mean age: 33.6, SD: 10.3 , range: $20-71)$.

Turkish Subjects (A5): Eighty-six Turkish students (60 female) volunteered to participate in Experiment A5 after being recruited via social media. Most subjects were students from Bilkent University (mean age: 23.5 , SD: 5.6, range: $15-52$ ). There was no monetary compensation.

Procedure. Subjects read a vignette in which a classmate cuts in line in front of them at a pay phone. As a result of cutting in front of the subject and making the phone call, the classmate avoids losing their winning lottery ticket, but the subject misses her bus and has to wait for the next bus. Subjects were randomly assigned to one of two conditions: in the large benefit condition the lottery was worth a large amount of money (for US subjects: \$1000); in the small benefit condition the lottery was worth a small amount of money (for US subjects: \$5). Monetary values were chosen by the experimenter most familiar with the tested culture to be similar in magnitude to the US amounts.

Materials. The following is the large benefit condition vignette given to American and Australian males. The sex of all the characters in the story was matched to the sex of the subject. Indian, Turkish, and Romanian versions had minor changes, e.g., "the classmate" was changed to a work colleague for Indian subjects, but all changes were held constant across conditions. The names were always gender-neutral names common in the tested culture. 
You are downtown at a mall shopping. Just when you're done you realize you forgot to call your roommate. You promised to call him when you finished shopping. The bus going from the shopping center back home leaves at 5:00 sharp, and it's about 4:50 now, but you have to call your roommate before you catch the bus.

There is a short line at the pay phone at the bus stop, and unfortunately you're not sure if you'll be able to call him before your bus leaves. If you miss the bus, you'll have to wait another hour for the next bus, and you really don't want to do that. You go to the back of the line at the pay phone and wait.

Finally, at 4:59, it is your turn to use the phone. If you hurry, you know you can still make the bus. When you're just about to pick up the receiver, a well-dressed guy you recognize from one of your classes pushes you out of the way while muttering, "Watch out." He grabs the phone and dials a number. A moment later, you see your bus pulling away and you know you'll have to wait another hour.

Please answer the following question before continuing on with the story: How angry would you be feeling at that moment? (circle a number)

$\begin{array}{lllllll}1 & 2 & 3 & 4 & 5 & 6 & 7 \\ \text { not at all } & & & & & & \end{array}$

[page break]

The story continues here:

As you pick up some of your dropped bags you hear him talking on the phone to his friend. "Alex, pick up if you're there! Alex? Good, you're still there. I just saw the numbers on that lottery ticket; I won. I think Pat threw it away with the rest of the stuff, though. You have to get it out of the trash before the garbage man comes at 5 . Is the trash still there?" He pauses for a second. "Great. Thanks a lot."

He hangs up the phone and mutters to himself, "I can't believe I almost lost a thousand dollar ticket."

Compared to your earlier answer, how much anger would you feel now? (circle a number)

\begin{tabular}{ccccccc}
-3 & -2 & -1 & 0 & +1 & +2 & +3 \\
much less anger & & \multicolumn{3}{c}{ the same anger } & & \\
much more anger
\end{tabular}

In all cultures, only a single word differed between conditions: in the last sentence the value of the lottery ticket was either a small amount or a large amount of money (e.g. for US subjects either "thousand" or "five").

\subsection{Results and discussion for Experiments A1-A5}

Stimulus check: Did the vignette provoke anger?

For the vignette to be appropriate as a stimulus for studying anger, imagining oneself in the scenario should elicit anger in subjects who do not yet know why the offender pushed them out of the way. It did. The initial anger ratings-those made before subjects learned why the cost was inflicted-were above the midpoint of the scale in all five cultures, ranging from a mean of 5.1-6.3 on a 7-point scale (see Table 1). These ratings were made before the independent variable (the value of the ticket) was introduced and demonstrates that the situation described in the text was sufficient to elicit anger.

Were subjects more angry when an offender harmed them for a small benefit rather than a large one? (prediction \#2)?

The data strongly support prediction \#2 (see Fig. 2). Independent samples t-tests showed the change in anger was significantly
Table 1

Initial anger scores before learning the offender's benefit.

\begin{tabular}{clllll}
\hline & US & Australia & Romania & India & Turkey \\
\hline Mean anger & 6.3 & 5.1 & 5.1 & 6.1 & 6.1 \\
$(\mathrm{SD})$ & $(0.78)$ & $(1.56)$ & $(1.63)$ & $(1.07)$ & $(1.16)$ \\
\hline
\end{tabular}

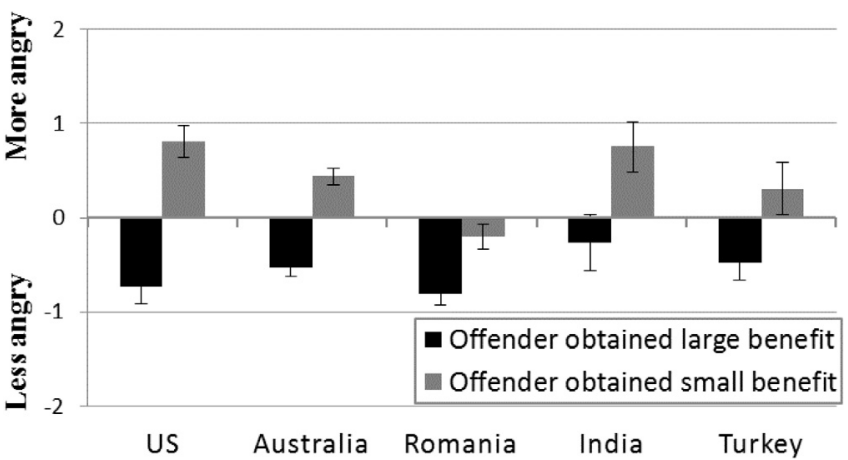

Fig. 2. Effect of offender's benefit on subject's anger. 
different between conditions in all tested cultures $(p<0.05$, twotailed). Effect sizes ranged from $d=0.39$ (in Romania) to 1.15 (US). See Table 3, prediction \#2, in Section 6. Additional details, analyses, and controls are reported in the Supplemental Online Materials.

\subsection{Experiment A6: Replication among Shuar foragers in the Ecuadorian Amazon}

The claim that anger has a species-typical design becomes stronger in proportion to the diversity of cultures tested. Although the original study and four replications (A1-A5) include populations from Eastern Europe, Asia Minor, Southern Asia, and two geographically distant countries from the Anglosphere, the individuals tested all live in advanced market economies with police and courts to resolve disputes. Our next test was in a culture that differs along those dimensions: the Shuar, an indigenous Amazonian society living in the southeastern neo-tropical forest of Ecuador (Jandial, Hughes, Aryan, Marshall, \& Levy, 2004; Patton, 2005). The Shuar hunt (with blowguns and shotguns), fish, gather, and practice slash-and-burn horticulture. Police are not present in Shuar villages, although they can be called into investigate following a homicide. Homicide rates for men are now much lower (Steel, 1999), but they were very high for the ancestors of people alive today (Patton, 2005). The Shuar have a culture of honor, and interpersonal conflicts are sometimes settled with the threat or use of violence. This makes them relevant to hypotheses about anger; ethnographic and experimental data indicate that people raised in cultures of honor are more likely to anger in response to perceived slights (Nisbett \& Cohen, 1996).

Will anger decrease among Shuar people in response to evidence that the offender gained a large benefit by inflicting a cost on them, as the welfare tradeoff hypothesis predicts? To find out, we administered vignettes similar to the one used in A1-A5 to Shuar people.

\subsubsection{Method for Experiment A6}

Subjects: Sixty-three adults ( 32 female) from five Shuar villages in southeastern Ecuador were read the vignettes and gave verbal responses (mean age: 30.2, SD: 14.1). Note that ages were available for only thirty subjects. All subjects were fluent in Spanish, and the study was conducted in Spanish. Compensation was provided in the form of public goods donated to the community (e.g., donations to the medical center) and was not contingent on any individual's participation.

Materials. A new vignette was required because many features of the vignette used in Experiments A1-A5 are unfamiliar to Shuar villagers. Instead, two vignettes were created: one for Shuar men and another for Shuar women. The vignettes had the same structure as in Experiments A1-A5: subjects first learned of a cost imposed on them, then they learn the magnitude of the benefit the offender obtained by imposing that cost. The male version involved a fellow villager borrowing the man's chainsaw without asking. The English translation is given below:

Imagine you leave your chainsaw in front of your home before going to a dinner that was taking place in your village. Your leader invited another group to dinner. You enjoy their company and have fun during the festivities. When you go back to your home later that night you see that your chainsaw is missing. You look around for it, but cannot find it. Then you see one of the male visitors carrying your chainsaw back to your home. The chainsaw looks like it has been used.

At this point subjects were asked how angry this would make them: not angry (1), a little angry (2), angry (3), very angry (4). After answering, subjects learned that their chainsaw had been taken to cut a fallen tree. In the small benefit condition, this was done for firewood. In the large benefit condition it was to free the truck that would take them home. The text read as follows:

You ask him why he took your chainsaw without asking. He says, "I needed it to cut a fallen tree [that was blocking the truck that is taking us home / for some firewood]." Would this statement make you more or less angry?

Subjects then reported their change in anger by verbal response: much less angry ( -2$)$, less angry ( -1$)$, no difference ( 0$)$, more angry (1), much more angry (2).

The female version was similar, but involved a cooking pot being taken in order to make some chicha (a pre-masticated alcoholic drink from the manioc plant):

Imagine you leave your cooking pot in front of your home before going to a dinner that was taking place in your village. Your leader invited another group to dinner. You enjoy their company and have fun during the festivities. When you go back to your home later that night you see that your cooking pot is missing. You look around for it, but cannot find it. Then you see one of the female visitors carrying your cooking pot back to your home. The cooking pot looks like it has been used.

After initial anger measures were taken, the subjects learned why the pot was taken:

You ask her why she took your cooking pot without asking. She says, "I needed it to brew some chicha for [the president of the Shuar Federation / my husband]." Would this statement make you more or less angry?

The large benefit condition was brewing chicha for the president (a high prestige individual); the small benefit condition was brewing it for her husband (an everyday activity).

\subsubsection{Results and discussion for Experiment A6}

Stimulus check: Did the vignettes provoke anger when subjects did not yet know the offender's reason? Yes. Average ratings were approximately 3 out of 4; Shuar men averaged 3.1 (SD 0.94); women 2.8 (SD 0.98).

Were subjects more angry when an offender harmed them for a small benefit rather than a large one? (prediction \#2)

For women, yes. When Shuar women learned they were harmed for a large benefit, they reported a large decrease in their anger compared to when they learned that the benefit to the offender was small (mean difference: $0.88, t(30)=2.66, p=0.01, d=0.98$ ).

For men, there was no significant difference between conditions, (mean difference: $0.16, t(29)=0.44, p=0.67$ ). This is most likely because we under-estimated the benefit of cutting firewood (the Shuar cook on wood fires). This benefit may be large enough that taking the chainsaw does not imply that the offender has a low welfare tradeoff ratio toward the subject. Follow up interviews were not conducted, so this explanation is speculative, but there is some empirical support for it: Shuar men's anger decreased significantly (compared to 0 ) when they learned that the chainsaw was taken to cut firewood (mean $=-0.62, \mathrm{SD}=1.0, t(12)=-2.1$, $p=0.06 ; d=1.22$ ). In other words, while the difference between conditions was not significant, Shuar men did become less angry when their realized the individual who took their property would receive a sizeable benefit for having done so.

\subsection{Summary and conclusion for Experiments A1-A6}

The recalibrational theory proposes that anger is triggered via cues of another's low welfare tradeoff ratio. When a cost is imposed on someone in order to acquire a benefit, the ratio of that cost to benefit indicates the maximum observed WTR in that 
Table 2

Initial anger scores before learning the subject's lunch was ruined.

\begin{tabular}{|c|c|c|c|c|c|}
\hline & US & Australia & Romania & India & Turkey \\
\hline Mean anger (SD) & $5.1(1.53)$ & $4.7(1.60)$ & $4.5(1.93)$ & $5.3(1.68)$ & $5.7(1.50)$ \\
\hline
\end{tabular}

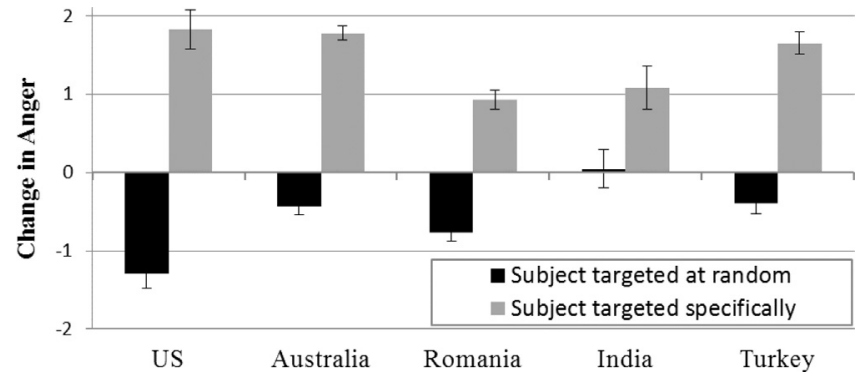

Fig. 3. Effect of specific versus random imposition of costs on anger.

circumstance. The larger the acquired benefit, the higher the WTR can be. Thus, when an angry person learns that a cost imposed on them was done to receive a large benefit, they become less angry (prediction \#2). This general pattern was confirmed across all six societies (see summary in Table 3 ).

\section{3. "Intentionality" as a cue of WTR engagement}

Intentions play a key role in anger. Specifically, unintentional costs cause less anger than intentional costs (Berkowitz \& Harmon-Jones, 2004; Epstein \& Taylor, 1967; Nickel, 1974; Ohbuchi \& Kambara, 1985). For anger to respond to the target's intentions, the anger system must perceive cues about what the actor knew at the time of the offensive act and use them to classify the act. Many researchers and philosophers defined "intentional" in terms of the knowledge of the outcome of an action (e.g. Forguson, 1989), though the subdivisions of "outcome" are unclear. In other words, which aspects of the outcome had to be known for it to be intentional - the cost, the benefit, the identity of the victim? Kaufmann (1970) defined an intentional aggressive act as one which is known by the actor to have a non-zero chance of inflicting harm on the target, i.e. the actor believed he was imposing a cost. Tedeschi and Felson (1994) defined an intentional act as "an act performed with the expectation that it will produce a proximate outcome of value to the actor," i.e. the actor believed she would attain a benefit. From an evolutionary point of view, the cues humans use to categorize behavior as intentional or not ought to depend on the reproductive consequences of using those cues ancestrally. In short, it will depend on why the concept of "intentions” evolved (see Tomasello, Carpenter, Call, Behne, \& Moll, 2005).

The recalibrational theory offers a theoretically-derived functional definition of intentions in the context of anger. Specifically, humans use a specialized computational operation to determine whether the observed WTR (i.e. the weighting put on the angry individual in that particular decision) accurately indicates the real, stable, WTR the target holds toward the angry individual (i.e. how much weight they would likely put on the angry person in future decisions). If the observed WTR does not accurately indicate the individual's actual WTR then the behavior will be categorized as "unintentional" and be less likely to trigger aggressive bargaining to recalibrate the WTR, though the angered person may negotiate the target's perception of the costs and benefits; e.g., "that hurt me more than you realize" (Sell, 2011b).
For a cost imposition to accurately indicate a low WTR (see Fig. 1), three elements must have been known to the person who imposed the cost at the time the action was taken: (i) the magnitude of the cost imposed (Kaufmann, 1970), (ii) the magnitude of the benefit gained by imposing that cost (Tedeschi \& Felson, 1994), and (iii) the identity of the individual on whom the cost was imposed. ${ }^{3}$ This last criteria exists because welfare tradeoff ratios are person-specific, so cost impositions clearly indicate the actor's WTR only when the actor knew the cost would be imposed on that specific person. This leads to prediction \#3:

- Prediction \#3: Holding the costs and benefits constant, anger will be more intense when the offender deliberately imposes the cost on the angry individual as opposed to imposing the cost without knowing the identity of the recipient.

\subsection{Experiments B1-B5: Is knowledge of the victim's identity a criterion of intentionality in anger?}

Prediction \#3 was tested with a short vignette about a practical joke. The joke involved an insult, with a potential loss of face in front of the subjects' classmates or workmates.

\subsection{Methods for Experiments B1-B5}

American Subjects (B1): Sixty-four undergraduates (43 female) from UCSB participated in this experiment for partial fulfillment of their introductory psychology class credit (mean age 18.4, SD 0.85 , range: $17-21$ ).

Australian and Romanian Subjects (B2 and B3): The same subjects who participated in experiments $A 2$ and $A 3$ also participated in B2 and B3. The order of the vignettes and condition were randomized.

Indian Subjects (B4): The recruitment method used in A4 was also used for B4. After the language and attention checks, data remained from eighty-four subjects (29 female, mean age: 31.9, SD: 9.9).

Turkish Subjects (B5): One hundred and seventy-seven (115 female) students volunteered and completed the survey online after being recruited from social media (mean age: 22.9, SD: 3.5, range 18 to 40 ).

Procedure. Subjects were given a questionnaire about another student who puts a banana slug in the subject's lunch during a class biology trip. In the specific condition, the jokester knew whose lunch it was; in the random condition the jokester did not know whose lunch it was at the time he put the creature in the lunch. Minor changes were made between cultures, e.g. Romanians are unfamiliar with banana slugs so a cockroach was used. The name of the prankster was always a common male name.

Materials. The following is the specific condition vignette for American subjects.

\footnotetext{
3 These three elements must be known in order for the ratio of the cost imposed to the benefit gained to accurately indicate the maximum WTR the actor has. However, there are other ways that a cost imposition, even lacking some of these elements, could indicate a low WTR. For example, assuming - reasonably - that humans take more precautions to avoid imposing costs on valued others, then the accidental imposition of a cost would indicate something about the WTR an individual has toward another, and variables such as the price of the precautionary act, and the magnitude of the cost imposed would presumably be relevant.
} 
You and a friend sign up for a biology class here at UCSB that requires you to go out with the class and observe wildlife in the forest. The Saturday trips take place between 10:00am and 3:00pm, so students bring bagged lunches along. The lunches are kept in the bus so they don't distract the wildlife.

You get to know the other students on the trip, but everyone pretty much stays with their lab partner. Everyone got to pick their lab partners, so you and your friend got to work together.

One student, Jimmy, is a bit of a prankster and occasionally tells an offensive joke or two. One day when everyone gets back to the bus, the TA [NB: Teaching Assistant] opens up the bin the lunches are kept in, and you see one of the lunches has been marked with a black magic marker. It reads: "At last, meet your intellectual equal." The TA notices the bag moving, and when he opens it a four-inch banana slug crawls out of it. Everyone cracks up laughing. One of his friends congratulates Jimmy on the joke. "Good one," he says. "Thanks," Jimmy replies.

It is your lunch. Everyone watches while you get your lunch and throw the slug aside.

Please answer the following question before continuing on with the story:

How angry would you be feeling at that moment? (circle a number)

$\begin{array}{lllllll}1 & 2 & 3 & 4 & 5 & 6 & 7 \\ \text { not at all } & & & & & & \text { very strongly }\end{array}$

*The story continues on the next page*

[Page break]

The story continues here:

As people continue to laugh at you, one of the other students whispers to Jimmy, "Did you know whose lunch it was?" Jimmy responds, "Yes."

In the random condition the last word was changed from "Yes" to "No." All other aspects of the vignettes were identical. Subjects then reported how much their anger changed on a Likert scale from -3 (much less) to +3 (much more).

\subsection{Results and discussion of Experiments B1-B5}

Stimulus check. For the vignette to be appropriate as a stimulus for studying changes in anger, imagining oneself as the victim of the prank should elicit anger in subjects who have not yet learned whether they, specifically, were the target of the prankster's joke. It did. Across all samples, the initial anger measurement was above the midpoint of the scale (see Table 2).

Did subjects who learned that the insult was not directed at them in particular feel less anger than those who learned that it was? (prediction \#3)

Yes. See Fig. 3. In all five countries, subjects' anger differed between the random target condition and the specific target condition, with generally large effect sizes ranging from $d=0.63$ to 2.6 (see Table 3, prediction \#3, in Section 6). In short, subjects became much more angry when they are specifically targeted by the prankster. Additional details, analyses, and controls are reported in the Supplemental Online Materials.

\subsection{Summary and conclusions for Experiments B1-B5}

There is little information from which to infer an actor's WTR toward a target if the actor did not know in advance who would suffer the cost of his actions. ${ }^{4}$ This predicts that subjects should be less angry when the actor didn't know who would be affected by his actions and more angry when he specifically targeted the subject (prediction \#3). This prediction was confirmed across the five cultures tested (time constraints associated with the fieldwork season prevented the planned tests among the Shuar). These results suggest that people use information about the offender's intentions to determine whether the costs inflicted and benefits gained accurately reflect the offender's welfare tradeoff ratio toward them.

\footnotetext{
${ }^{4}$ While intentional acts are much more accurate indicators of someone's WTR there are cues that are perceptible even from acts that strike random targets (see Footnote 3). Using this example, the prankster risked imposing a cost on the subject a risk that was later realized. If he valued the subject's welfare highly he would have sought to avoid such risks. He also risked imposing costs on individuals that the subject might have cared about. Additionally, his actions may indicate that he feels overly entitled and likely has a deflated WTR toward many individuals, including the subject. This last reason is presumably why arrogance - particularly when the arrogant individual is not high status or formidable - is inherently anger-provoking even in the absence of a particular affront.
} 


\section{The content of anger-based arguments}

Though rarely empirically studied, arguments are, by far, the most common behavioral response to anger (Averill, 1982), and any comprehensive theory of anger must explain the structure of such arguments. The recalibrational theory holds that arguments are attempts to recalibrate the target's welfare tradeoff function as well as other variables relevant to the resolution of the conflict (e.g., relative value placed on the contested act, resource, or event). This information exchange during bargaining has many evolutionary analogs; e.g., animals during conflicts of interest frequently signal their fighting ability (Enquist, Leimar, Ljungberg, Mallner, \& Segerdahl, 1990; Huntingford \& Turner, 1987). Furthermore, some species are known to send signals of their valuation of a contested resource; e.g., bald eagles raise their crop to show the distention of their gullet to opponents when fighting over food (Hansen, 1986), male elephants signal through visual, auditory, and olfactory channels their musthstate (i.e., reproductive state) to demonstrate the high value they place on a contested female (Poole, 1989). While eagles signal their hunger via a different channel than a human bargaining over whether she is to be allowed to take the day off of work, the conceptual grammar of the message is identical: "I value this highly, and therefore you should cede the resource to me." Such an argument will sometimes recalibrate the opponent and lead to the resolution of the conflict in favor of the arguer without any escalation to overt aggression, e.g., bald eagles that see the empty stomach of their opponent are more likely to relinquish the food (Hansen, 1986), and larger non-musth elephants will often defer to smaller elephants who are in a musth state (Poole, 1989). This indicates that favorable outcomes in such bargaining are not just based on a superior ability to inflict costs, but that the more formidable animal must also take into account how much effort his or her adversary will be designed to invest in obtaining or defending the resource based on differential valuation.

Thus, humans - like other animals - should be well designed to manipulate perceptions of a conflict in their own favor. Indeed, the design in humans is likely much more sophisticated than non-humans because of our uniquely complex communication system (i.e. language) and richness of representation. Specifically, the human mind is predicted to be equipped with mechanisms that come online when an individual is the target of anger and function to deactivate the other person's anger mechanism. The existence of this mechanism is supported by research showing specialized perceptual systems that respond to the anger face (Feldmann-Wustefeld, Schmidt-Daffy, \& Schubo, 2011; Öhman et al., 2001). Furthermore, the structure of the anger-disabling strategies can be predicted from the form of the anger system itself, and thus provide testable hypotheses about the recalibrational theory. For example, one way to deactivate anger is to allow it to fulfill its function and recalibrate one's welfare tradeoff function toward the angry individual. We hypothesize that apologies are an evolved response that work via this route, but we do not address specific predictions from this perspective in this paper.
Another way to deactivate anger is to counteract its input conditions. If $A$ and $B$ trigger anger, then convincing angry individuals of not-A and not-B would mitigate the costs of anger by essentially turning it off. Predictions 1-3 relate to the trigger of anger in the angry individual, and thus each produces a converse prediction in the target of anger. When confronted by an angry individual on whom one has imposed a cost, targets of anger should favor statements consistent with holding a high WTR toward the angry individual. Specifically, offenders should argue that:

- Prediction \#4: the cost the offender imposed was small.

- Prediction \#5: the benefit the offender received as a result of imposing the cost was large.

- Prediction \#6: the offender imposed the cost on an individual whose identity was not represented in advance.

4.1. Experiments C1-C6: When confronted with another's anger, do subjects prefer arguments that demonstrate they have a high WTR toward the angry individual?

In Experiments C1-C6, American, Australian, Romanian, Indian, Turkish, and Shuar subjects were asked to imagine that they had provoked anger in another person. Subjects were then asked to select arguments they would make if they wanted to convince that person that what they had done was not so bad as to warrant anger.

\subsection{Methods for Experiment C1-C5}

American Subjects (C1): Fifty-six undergraduates (35 female) at UCSB participated for partial fulfillment of their introductory psychology class credit (mean age $18.2, \mathrm{SD}=0.54$ ).

Australian Subjects (C2): One hundred and forty-eight (115 female) undergraduate students at Griffith University participated for course credit (mean age 21.5, SD: 4.3).

Romanian Subjects (C3): Forty-two undergraduates (39 female) from the University of West Timisoara volunteered to participate (mean age 23.1, $\mathrm{SD}=6.35$ ).

Indian Subjects (C4): The recruitment method used in A4 was also used for $\mathrm{C} 4$. After language checks data remained from eighty-five subjects (33 female; mean age: 32.9 , SD: 8.9).

Turkish Subjects (C5): The same subjects who participated in Experiment B5 participated in $\mathrm{C} 5$. The order of the scenarios and arguments were randomized.

Procedure. Subjects were given a questionnaire that contained three scenarios. For each scenario, subjects were asked to imagine that they had inflicted a cost on someone else to gain a benefit for themselves. They were presented with a list of arguments that they could make on their own behalf, and asked to rate each one.

Materials. Subjects received instructions followed by the scenarios. The instructions and a sample scenario follow. In brackets we show the theoretical categories for each argument; these did not appear in the stimuli. 
We are interested in how people make arguments. Below we will describe some situations in which someone is mad at you because of something you did. We will then list a series of statements that you could bring up in your argument. It is your job to decide which statements would strengthen your case, and which ones would weaken it.

For example, if a teacher accused you of cheating on a test, you would not defend yourself by saying, "My notes were lying open on the floor." That would weaken your case.

Several conflicts are described on the pages that follow. Read them carefully. Below each are a series of statements with a blank space before them. Some of these statements may be contradictory.

Rate each statement as if it is the only argument you are going to make on your own behalf. Use this scale:

$\begin{array}{ccccccc}-3 & -2 & -1 & 0 & +1 & +2 & +3 \\ \begin{array}{lll}\text { definitely weakens } \\ \text { my case }\end{array} & & & & \text { definitely strengthens } \\ \text { my case }\end{array}$

- If a statement would strengthen your case, assign it a positive number. (For example, if a statement helps your case a lot, then assign it a +3 ; if it would only help your case a little, then assign it a +1.)

- $\quad$ Put a 0 next to statements that don't help or hurt your case.

- $\quad$ Assign negative numbers to statements that would definitely weaken your case. (For example, if a statement hurts your case a lot, then assign it a -3 ; if it would only hurt your case a little, then assign it a-1.)

There are no trick answers. We're interested in your gut reaction.

[page break]

Imagine that you ruined one of your friend's sweaters. It is completely useless to him now, and he is very upset about it. You want to argue that what you did was not that bad. How much would each argument strengthen or weaken your case? Assume that he will believe you when you make the statement.

There were three scenarios in total. In addition to the scenario listed above, there was one in which the subject talks on the phone instead of busing tables while at work, angering a co-worker. In another, the subject steals prescription drugs from a pharmacy, angering the owner of the pharmacy.

Subjects were asked to choose statements that would help their case if they wanted to argue that what they did was not "that bad." This wording was chosen to explore intuitions about welfare tradeoffs - in contrast to apologies which are often accompanied by admissions, e.g., "I understand I hurt you a lot..." The order of the statements was counter-balanced across subjects and scenarios.

\subsection{Results and discussion for Experiments C1-C5}

Ratings for statements about the size of costs and benefits are averaged over the three scenarios. Statements about random versus specific victims were presented in only one scenario (not knowing the victim's identity was plausible in the sweater scenario above, but not in the others). Due to a programming error, data on random vs. specific victims were unavailable for Turkish subjects (C5).

Which arguments do subjects prefer when confronted with anger?

Results are shown in Fig. 4. Predictions \#4-6 hold that subjects will prefer arguments indicating that their welfare tradeoff ratio toward the angry individual is high and spurn arguments that indi- 
cate their WTR is low. Paired samples t-tests were run for each culture comparing ratings of each statement with its opposite (e.g. high cost statements were compared to low cost statements). All predictions were confirmed; effect sizes were very high (ranging from $d=1.2$ to 8.0) and invariantly significant (see Table 3 in Section 6). Keep in mind that this experiment was done within subjects, meaning that subjects likely rated the arguments against their opposite (e.g. recognizing that the small cost statement was better than its complementary large cost statement). This may have inflated the effect sizes, but could not have produced the pattern of effects unless subjects truly preferred high WTR statements to low WTR statements.

\subsection{Experiment C6: Replication among the Shuar of Ecuador}

Predictions \#4 and \#5 were also tested among the Shuar. Two scenarios were read to subjects in which they impose a cost on a neighbor. Subjects then rated arguments they could make in their own defense.

\subsubsection{Methods for Experiment C6}

Subjects: Ninety subjects (50 female) from five Shuar villages were read one of two vignettes (mean age: 33.12, SD: 13.0, $n=52$ ). Note that ages were available for only 52 of the 90 subjects. See Experiment A6 for more detail.

Procedure and Materials: Subjects were read one of two scenarios, chosen at random. In one, the subject's dog attacked their neighbor's chickens; in the other, the subject failed to purchase some medicine for their neighbor. Because the same subject pool was also used for Experiment D6, each subject was read only one scenario for Experiment C6 and the other for Experiment D6.

The first scenario is given below:

Imagine you had to tie up your dog because your dog was killing chickens in your neighborhood. One day you come home and find that your dog attacked your neighbor's chickens. When you meet your friend, he is very angry about what your dog did. Your friend complains to you about it. You feel you have a good reason for not tying your dog.

Subjects then responded to a series of statements that they could say to their friend. They were asked to indicate how they would respond to their friend. They rated each statement as follows: very poor statement $(-2)$, poor statement $(-1)$, no difference $(0)$, good statement (1), very good statement (2). The statements were:

At least the dog only disturbed the chickens but didn't kill them. [small cost to friend]

The dog only killed one chicken. [small cost to friend]

The dog only killed ten chickens. [large cost to friend]

I let the dog go free because I had to use the rope for my hammock. [small benefit for subject]

I had to untie the dog because there was a jaguar near my house. [large benefit for subject]

\subsubsection{Results and discussion for Experiment C6}

Results were similar to those from the other five cultures (see Table 3 in Section 6). Consistent with prediction \#4, subjects preferred statements indicating that they had imposed only a small cost on their neighbor over statements that they imposed a large cost, mean difference $=1.20, \mathrm{SD}=1.07$, paired samples $t(89)$ $=10.65, p=10^{-16}, d=2.3$. Prediction \#5 was also confirmed for Shuar subjects: Shuar preferred to argue that they benefited greatly by imposing the cost rather than benefiting only a little (mean difference $=0.67, \mathrm{SD}=1.30$, paired samples $t(89)=4.92$, $p=0.000004, d=1.0$ ). As with subjects from other countries, Shuar subjects preferred arguments consistent with holding a high WTR toward the individual they had harmed.

\subsection{Summary and conclusions for Experiment Set $C$}

Experiments C1-C6 demonstrate that subjects prefer arguments suggesting that their action was consistent with their having a high welfare tradeoff ratio toward the angry individual. This general pattern was found reliably across all tested societies. In conclusion, subjects' argument preferences appear well-designed to deactivate an anger system that is triggered by indications of a low welfare tradeoff ratio. ${ }^{5}$

\section{Experiment Set D: Replication and converging evidence - Which arguments actually lessen anger?}

Experiment Set D serves as the mirror image of Experiment Set C. It is designed to provide converging evidence for the hypotheses tested in Experiment Sets A and B, as well as to test whether subjects' preferred arguments from Experiment Set $C$ actually diffuse anger. They are predicted to: if anger-based arguments involve dueling perceptions about variables that reveal WTRs, then those arguments preferred by subjects in Experiment Set $\mathrm{C}$ should lower anger if believed by the angry individual they are directed at.

In Experiments D1-D6, American, Australian, Romanian, Indian, Turkish, and Shuar subjects were given the scenarios used in Experiments $\mathrm{C} 1-\mathrm{C} 6$, but instead of the subject being the person who imposed the cost, the text was rewritten so that the subject was the person on whom the cost was imposed. Subjects were then asked to rate the arguments from Experiment Set $C$ to indicate which would exacerbate their anger and which would diminish their anger. This design also allows us to replicate predictions 1-3. Anger should be exacerbated by information implying that the cost imposed was large, the benefit gained by the offender small, and the identity of the victim known (see Table 3 in Section 6).

\subsection{Methods for Experiments D1-D5}

American Subjects (D1): Sixty-four undergraduates (43 female) from UCSB participated for partial fulfillment of their introductory psychology class credit (mean age $18.4, \mathrm{SD}=0.85$ ).

Australian Subjects (D2): One hundred and seventy-four undergraduates (124 female) from Griffith University participated for partial course credit (mean age 22.2, SD = 5.7).

Romanian Subjects (D3): Forty-seven undergraduates (28 female) from the University of West Timisoara volunteered to participate (mean age: $20.1, \mathrm{SD}=3.32$ ).

Indian Subjects (D4): The recruitment method used in A4 was also used for D4. After language checks, data remained from eighty-nine subjects (33 female; mean age: 33.4, SD: 8.92).

Turkish Subjects (D5): The same subjects who participated in Experiment A4 participated in D4. The order of the scenarios and arguments were randomized.

Materials. Subjects were given a questionnaire that contained three scenarios based on those in Experiments C1-C5. These scenarios were rewritten so that the subject was the person on whom the cost was imposed. The example from Experiment $\mathrm{C} 1$ is shown here in rewritten form:

\footnotetext{
5 We note that such patterns may also function to sway third parties (see McCullough, Kurzban, \& Tabak, 2013). The presence of third parties complicates these analyses as well, particularly around issues of shame (Sznycer, De Smet et al., 2016). For example, in physical contests of strength men will often insist that the opponent did not hurt them greatly, e.g. "I barely felt it when you punched me." Bringing in additional psychological adaptations complicates the analysis of arguments, but in ways that make sense with the consideration of each additional system. The data presented here were elicited specifically to look at cases of anger in which one individual imposes a cost on another to receive a benefit and argues with the angry person that their behavior was acceptable.
} 
We are interested in how people react to arguments. Below we will describe some situations in which you are mad at someone because of something they did. They don't seem to think what they did was very bad, but you do (at least at first). We will then list a series of facts that might relate to your anger. It is your job to decide which facts would make you more angry and which facts would make you less angry. Some of these facts may be contradictory. Rate each fact as if it is the only fact you are considering. Use this scale:

$$
\begin{array}{llllllll}
-3 & -2 & -1 & 0 & +1 & +2 & +3
\end{array}
$$

definitely makes me

definitely makes me

less angry

more angry

- If a fact would make you more angry, assign it a positive number. (For example, if a fact makes you a lot more angry, then assign it a +3 ; if it would only make you a little more angry, then assign it a +1 .)

- $\quad$ Put a 0 next to facts that don't affect your anger.

- Assign negative numbers to facts that would definitely make you less angry. (For example, if a fact makes you a lot less angry, then assign it a -3 ; if it would only make you a little less angry, then assign it a -1.)

There are no trick answers. We're interested in your gut reaction.

[page break]

Imagine that a friend ruined one of your sweaters. It is completely useless now, and you are very upset about it. He doesn't think what he did was very bad. How would each fact affect your anger?

You got the sweater at a garage sale for a dollar. [small cost to subject]

Your grandmother had knit you the sweater before she died. [large cost to subject]

He ruined your sweater by using it to clean his tub. [small benefit for offender]

He ruined your sweater by using it to stop the bleeding from a gash on his head caused by a car crash. [large benefit for offender]

He didn't know it was your sweater when he ruined it. [random victim]

He knew it was your sweater when he ruined it. [specific victim]

For each scenario, the subjects were given the same list of possible statements from Experiment $\mathrm{C} 1$ that could pertain to the story (the statements were rewritten when necessary to maintain the role of the subject as the person on whom the cost was imposed). Subjects rated the statements from -3 (definitely makes me less angry) to +3 (definitely makes me more angry).

\subsection{Results and discussion for Experiments D1-D5}

Results are shown in Fig. 5. Data were analyzed by paired samples t-tests comparing the facts of each type to their opposite (e.g. large cost statements across scenarios compared to small cost statements across scenarios). In sum, indications that the offender had a low welfare tradeoff ratio toward the subject made them more angry in every tested culture. Specifically, subjects were more angry when they learned the cost imposed on them was large rather than small (prediction \#1), the benefit gained by the offender was small rather than large (prediction \#2), and that the offender knowingly imposed the cost on the subject in particular rather than at random (\#3). Effects were very large (ranging from $d=1.6$ to 6.9) and highly significant in every tested culture (see Table 3 in Section 6, predictions \#1-\#3). We note that, as in Experiment Set C, these data were gathered within-subjects, which may result in larger effect sizes.

\subsection{Experiment D6: Replication among the Shuar of Ecuador}

Experiments D1-D5 were replicated among the Shuar using the rewritten materials from Experiment C6.

\subsubsection{Methods for Experiment D6}

Subjects: Fifty-two subjects (30 female) from five Shuar villages were read one of two vignettes, mean age: 33.29 , SD: $12.0, n=31$. Note that ages were only available for 31 of the 52 subjects. See Experiment A6 for more detail.

Materials: One of two scenarios was read to each subject. In each, the subject's neighbor imposed a cost on them. Because the same subjects also participated in Experiment C6, the scenario read to them in D6 was not the scenario read to them in C6. The structure of the scenarios was the same as Experiments D1-D5. 


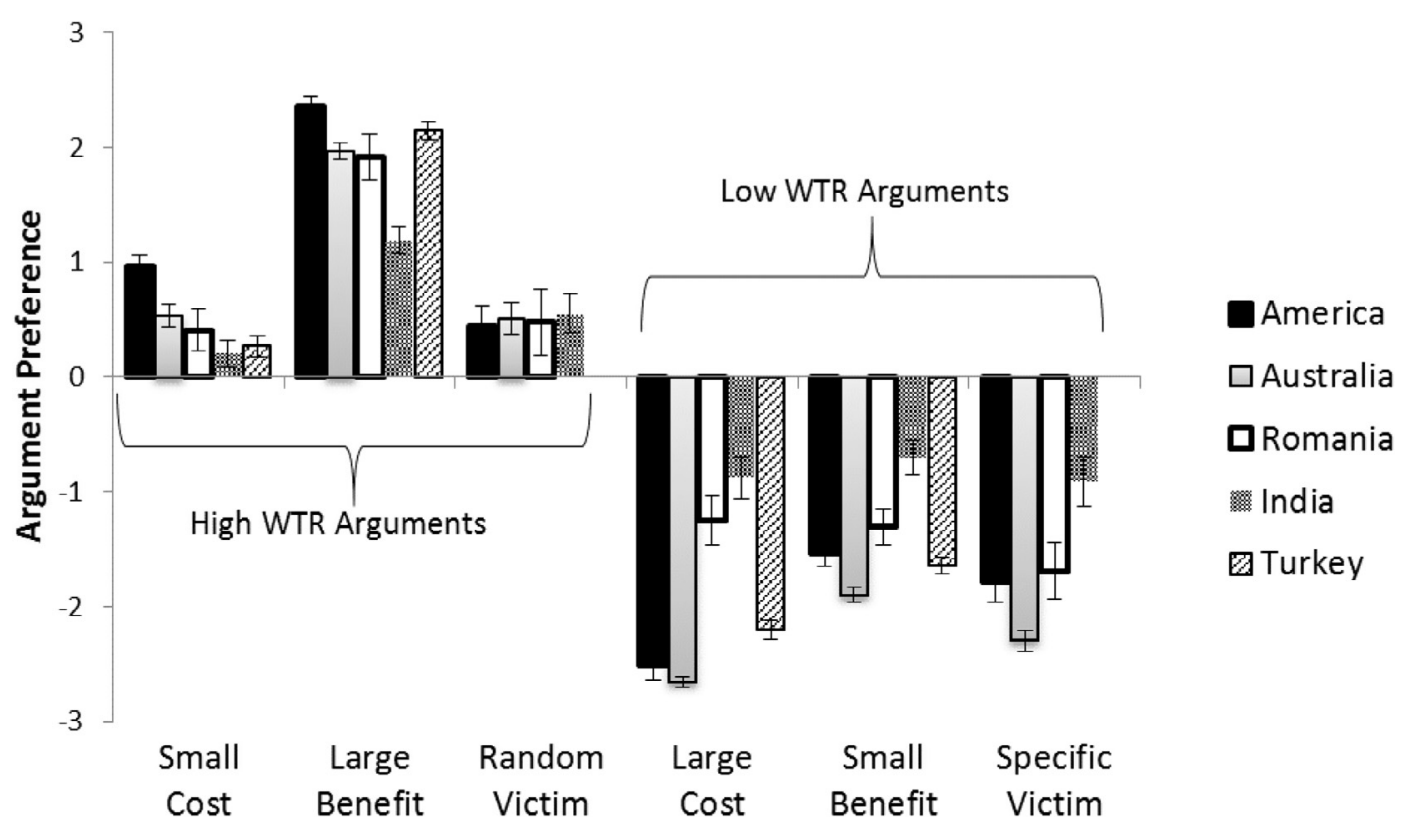

Fig. 4. Which arguments do targets of anger prefer?

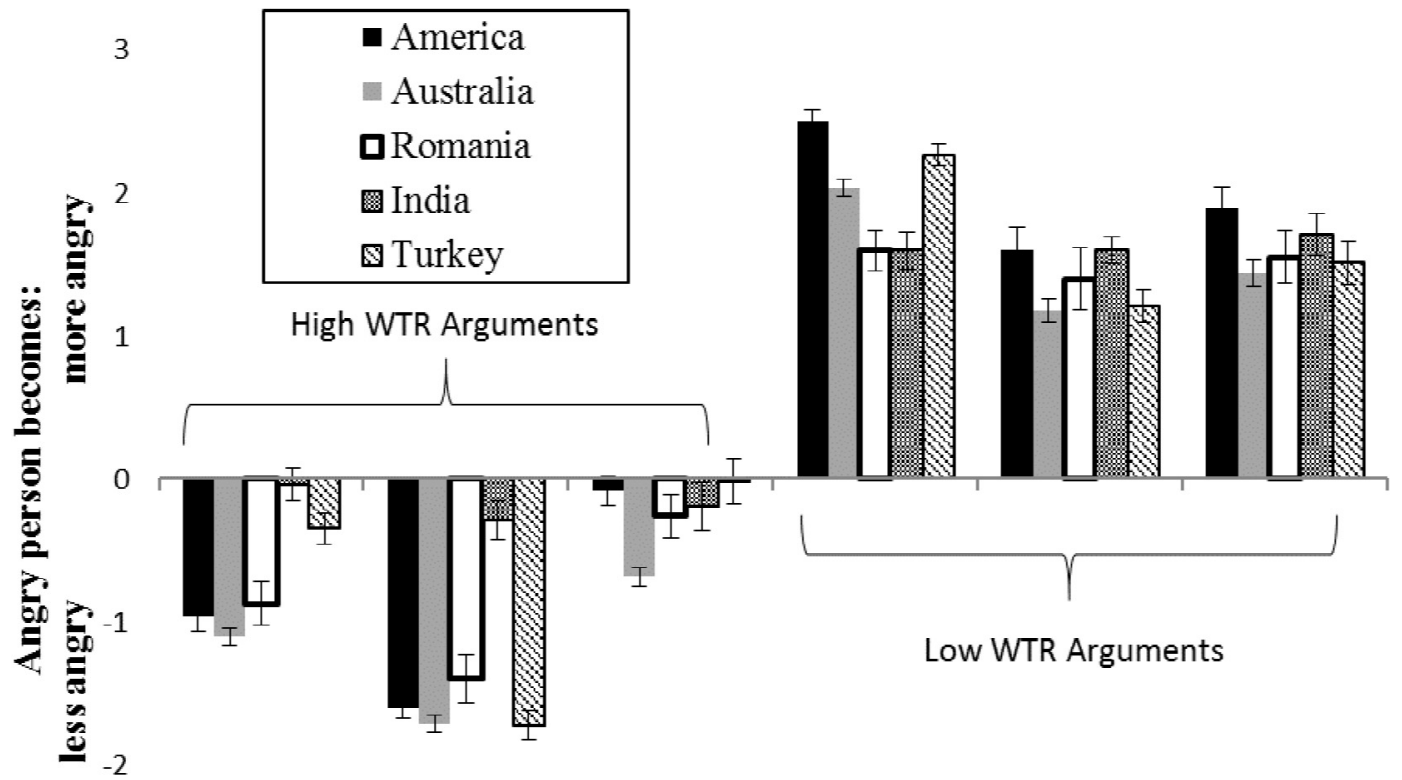

$-3$

$\begin{array}{cccccc}\text { Small } & \text { Large } & \text { Random } & \text { Large } & \text { Small } & \text { Specific } \\ \text { Cost } & \text { Benefit } & \text { Victim } & \text { Cost } & \text { Benefit } & \text { Victim }\end{array}$

Fig. 5. Which statements assuage or exacerbate another's anger?

The dog-killing-chickens scenario presented in C6 was rewritten so that the subject was the victim-that is, the person who owned the chickens. The sex of the friend in the scenario was matched to the subject. The other scenario (female version) is given below. (In C6, the subject was the person traveling to town rather than the one who wanted medicine).

Imagine a friend is making a trip into town to purchase some goods. You need some medicine and you ask your friend to buy the medicine for you. Your friend agrees to buy you the medicine and you give your friend $\$ 20$ to buy it.
Your friend goes to town and buys her goods. She comes back to the village without the medicine. You are very angry that she did not buy the medicine.

You complain to your friend that she didn't buy the medicine. She feels she has a good reason for not getting the medicine. What can she tell you to make you less angry?

Subjects then indicated how their anger would be affected by a series of statements: much less angry $(-2)$, less angry ( -1$)$, no difference (0), more angry ( 1 ), much more angry (2). 
Your fever is gone now anyway. [small cost to you]

The nurse will be here tomorrow with the medicine anyway. [small cost to you]

A medical brigade will be here next month with the medicine. [large cost to you]

Your fever will be gone in three weeks anyway. [large cost to you]

I didn't get the medicine because I spent the $\$ 20$ on beer. [small benefit gained by the offender]

I didn't get the medicine because I hurt my leg very badly with a machete and I had to use the $\$ 20$ for the doctor. [large benefit gained by the offender]

I didn't get the medicine because the store was closed for the day, so I would have had to stay in town until the next day, and I didn't have money to stay the night there [large benefit gained by the offender]

\subsubsection{Results and discussion for Experiment D6}

Results replicated the pattern found among American, Australian, Romanian, Turkish, and Indian subjects. Averaged across statement types and both vignettes, Shuar subjects calibrated their anger to the magnitude of the cost imposed on them, becoming more angry when confronted with high cost statements $(\mathrm{M}=0.32, \mathrm{SD}=1.37)$ and much less angry in response to low cost statements $(\mathrm{M}=-1.25, \mathrm{SD}=0.62)$. The difference between them was highly significant, paired samples $t(52)=7.77, p=10^{-8}$, $d=2.1$. Consistent with prediction \#2, anger decreased much more when the benefit gained by the offender was large $(\mathrm{M}=-1.04$, $\mathrm{SD}=0.82)$ rather than small $(\mathrm{M}=-0.24, \mathrm{SD}=0.87)$, paired samples $t(51)=-4.71, p=0.00002, d=1.3$.

\subsection{Summary and conclusions for Experiment Set $D$}

The results of Experiments D1-D6 demonstrated that subjects in Set C were correct: The statements offenders (those in Experiment Set C) thought would strengthen their case were precisely the same kinds of statements that made victims (those in Experiment Set D) less angry. Moreover, the statements that Set $\mathrm{C}$ subjects thought would weaken their case were exactly those that made Set D subjects more angry (see also Sznycer, Schniter, Tooby, \& Cosmides, 2015; Sznycer, De Smet et al., 2016). Furthermore, the results of Experiment Sets A and B were replicated. Across six cultures, subjects became more angry when the cost imposed on them was large rather than small, when the offender gained a smaller rather than a larger benefit, and when the offender had specifically targeted them. Taken together, the results show that cost impositions that imply that the offender's welfare tradeoff ratio is low trigger anger.

\section{General results and discussion}

Six predictions were derived from the recalibrational theory's account of how anger is triggered and scaled by cost-inflictions. All hypotheses were supported across a range of cultures (see Table 3). Collectively, the experiments presented herein support the view that anger is reliably evoked when information reveals that another individual holds too low a welfare tradeoff ratio toward the angry person.

\subsection{Anger and arguments}

This data also support a theoretical framework in which angerbased arguments can be understood as attempts by each individual to modify the perceptions of their interlocutor in ways that allow recalibration of their respective anger and welfare tradeoff functions. The data indicate that the targets of anger - when prompted to defend their actions rather than apologize - will deploy arguments designed to demonstrate a high WTR toward the angry individual. This account is also consistent with prior research and theorizing on intentional harms, e.g., individuals are predicted to argue that they did not know that the magnitude of the cost they imposed would be so large (see Kaufmann, 1970). Unlike previous accounts, this explanation can be derived directly from the evolutionary functional logic of the theory: an individual who intended to impose a smaller cost may have a high WTR toward the individual on whom the cost was imposed because the WTR - by definition - delineates acceptable cost-benefit transactions.

The structure of anger-based arguments will also depend heavily on the triggering conditions of anger, because the variables that indicate a low WTR will depend on the mental structure that leaked information about the WTR. This paper employed the most common trigger of anger: a cost infliction that embodied too low a WTR. However, others exist and will need to have their computational structure mapped separately. For example, information about a person's WTR can leak through their estimates of WTRcalibrating factors such as formidability, cooperative value, attractiveness, and so forth (Preston \& Kimberley, 1987; Sell et al., 2009; Sell et al., 2016).

Table 3

Predictions and summary of effect sizes (Cohen's $d$ ) across Experiments A through D.

\begin{tabular}{|c|c|c|c|c|c|c|}
\hline \multirow[b]{2}{*}{ Predictions } & \multicolumn{6}{|c|}{ Experiment set: Effect size $d$} \\
\hline & US & Australia & Romania & India & Turkey & Shuar \\
\hline $\begin{array}{l}\text { Subjects are more angry when: } \\
\text { \#1 larger costs imposed on them }\end{array}$ & D: $6.9^{* * *}$ & $\mathrm{D}: 6.1^{* * *}$ & $\mathrm{D}: 3.0^{* * *}$ & D: $1.9^{* * *}$ & $\mathrm{D}: 4.4^{* * *}$ & $\mathrm{D}: 2.1^{* * *}$ \\
\hline \#2 smaller benefits gained by offender & $\begin{array}{l}\text { A: } 1.2^{* * * *} \\
\text { D: } 6.9^{* * *}\end{array}$ & $\begin{array}{l}\text { A: } 0.82^{* * *} \\
\text { D: } 5.5^{* * *}\end{array}$ & $\begin{array}{l}\text { A: } 0.39^{* * *} \\
\text { D: } 4.1^{* * *}\end{array}$ & $\begin{array}{l}\text { A: } 0.52^{*} \\
\text { D: } 1.6^{* * *}\end{array}$ & $\begin{array}{l}\text { A: } 0.52^{*} \\
\text { D: } 5.5^{* * *}\end{array}$ & $\begin{array}{l}\text { A: } n . s .(m) \\
\text { A: } 0.98(\mathrm{f})^{* *} \\
\text { D: } 1.3^{* * *}\end{array}$ \\
\hline \#3 they are specifically targeted by offender & $\begin{array}{l}\text { B: } 2.6^{* * *} \\
\text { D: } 2.4^{* * *}\end{array}$ & $\begin{array}{l}\text { B: } 1.9^{* * *} \\
\text { D: } 2.7^{* * *}\end{array}$ & $\begin{array}{l}\text { B: } 1.1^{* * *} \\
\text { D: } 2.5^{* * *}\end{array}$ & $\begin{array}{l}\text { B: } 0.63^{* *} \\
\text { D: } 1.8^{* * *}\end{array}$ & $\begin{array}{l}\text { B: } 1.5^{* * *} \\
\text { D: } 1.8^{* * *}\end{array}$ & Not tested \\
\hline $\begin{array}{l}\text { Targets of anger argue: } \\
\text { \#4: "I imposed a small cost" }\end{array}$ & C: $6.9^{* * *}$ & C: $5.1^{* * *}$ & C: $2.0^{* * * *}$ & C: $1.3^{* * *}$ & C: $2.7^{* * *}$ & $\mathrm{C}: 2.3^{* * *}$ \\
\hline \#5: "I did it for a large benefit" & C: $6.9^{* * * *}$ & C: $8.0^{* * *}$ & C: $4.1^{* * * *}$ & $\mathrm{C}: 2.1^{* * *}$ & C: $5.5^{* * *}$ & C: $1.0^{* * * *}$ \\
\hline \#6: "I didn't impose cost on you in particular" & C: $5.5^{* * *}$ & C: $3.0^{* * *}$ & C: $1.6^{* * *}$ & C: $1.2^{* * *}$ & Not tested & Not tested \\
\hline
\end{tabular}

${ }^{*} p<0.05$, two-tailed.

** $p<0.01$, two-tailed.

$p<0.001$, two-tailed. 
Because there are multiple channels that leak information about WTRs, arguments can sometimes indicate a high WTR through one channel but low WTR through another. For example, anger can be triggered by a cooperative partner's willingness to replace you with another; this is because WTRs toward friends and romantic partners are indicated -- in part - by one's estimation of the longevity of the relationship - "I will love you until July" is a weaker signal of WTR than "I will love you forever" (Tooby \& Cosmides, 1996). More simply, anger can be triggered by an indication that a loved one is considering leaving you. Therefore, if a man were caught cheating on his wife, and she confronted him, her anger can be triggered by two simultaneous channels: one, she is angry because he indicated a willingness to replace her with another woman, and two, she is angry because he engaged in an act that imposed a large cost on her for a relatively small benefit. The man could counter the cost-infliction channel by claiming that the benefit he received for imposing that cost was very large (e.g., "But she was so beautiful...") but this simultaneously intensifies the signal through the other channel, i.e., it indicates that he is more likely to replace his wife with the other woman. On the other hand, he could counter the jealousy-channel of anger by claiming that the other woman meant nothing, and was unattractive, but this would intensify the cost-infliction channel by indicating that he decided to impose this painful cost on his wife for a trivial benefit. The existence of these multiple effects on anger is crucially important because they present a difficult - possibly insurmountable - problem for theories of anger based on associationism (see Berkowitz, 1990). This is because the anger mechanism responds in two different contradictory ways to the same piece of information, e.g. the husband claiming his lover was attractive. This fact cannot be modeled as an association between that information and the triggering of anger.

\subsection{Alternative theories of anger}

While many of the results documented in this paper conform to intuition, it is worth noting that they are - in their totality - inconsistent with a number of theoretical approaches to anger.

\subsubsection{Equity theory}

Equity theory was proposed as a general theory of human behavior that could be applied to many domains of human life (Berkowitz \& Walster, 1976; Walster, Berscheid, \& Walster, 1973). Later, Donnerstein and Hatfield (1982) tested the fit between data on anger and aggression and the predictions derived from equity theory with mixed results (for a related explanation see Relative Deprivation Theory, e.g. Smith \& Pettigrew, 2015). Equity theory, as applied to anger, predicts that anger is designed, to some extent, to make outcomes more equitable between the angry individual and the target of anger. Those who are "under benefited" inflict costs on those who are "over benefited" in order to even out the inequality. This predicts that the more a person benefited as a result of imposing a cost, the more angry the victim should feel, e.g., if someone imposed a cost of 5 in order to receive 5 then the inequality is 10 ; while if they imposed the same cost to receive a benefit of 2 the inequality would be only 7 .

Thus, the equity theory account of anger would predict a positive relationship between anger and the benefit the offender received as a result of the offense. These hypotheses are the opposite of predictions \#2 and \#5 and are contradicted by data from US, Australian, Romanian, Turkish, Indian, and Shuar subjects as documented in Experiment Sets A, C, and D.

Finally, the recalibrational theory predicts that anger will be caused by inequality only when the bargaining power of the two parties is equal. It can predict anger even in the beneficiary of an unequal welfare tradeoff where the relative bargaining power "entitles" her or him to an even more unequal tradeoff. This does not demonstrate that equity has no role in anger (we believe that it does), nor do the data demonstrate that an individual cannot become angry when another benefits greatly from a relationship while the angry individual benefits little. ${ }^{6}$ Rather, the data show that equity theory cannot account for the cognitive structure of anger when it comes to one-shot cost impositions or the arguments that they generate.

\subsubsection{Social constructivism and cultural calibration}

Classic work on the design of anger-based argumentation (Averill, 1982, 1983) laid bare rich detail to these social interactions that contradicted the simplistic animal models of early aggression theories, e.g. the frustration-aggression model (Berkowitz, 1988; Dollard, Doob, Miller, Mowrer, \& Sears, 1939), and drive-reduction theory (Hull, 1943). The complex nature of the arguments was ascribed to social products that serve social functions, "emotions serve a function within the social system, or at least are correlated with other behaviors that have a social function," (Averill, 1983, p. 1146). While the hypothesis that culture generates the major features of the anger system without the guidance of evolved design has been largely discarded (though see Barrett, 2017; Barrett \& Russell, 2014), anger is - nonetheless - calibrated by culturally-varying features of the social ecology (Matsumoto, Hee Yoo, Nakagawa, \& 37 Members of the Multinational Study of Cultural Display Rules, 2008; Scherer \& Brosch, 2009). This leaves the possibility that culturally variant, or perhaps even universal, features of anger could have been the product of cultural evolution that serves a societal benefit. ${ }^{7}$

Against that view, the data presented in this paper adds to a body of research showing that the underlying computational architecture of anger triggers is plausibly universal to the species (Alonso-Arbiol et al., 2011; Scherer \& Wallbott, 1994; Wallbott \& Scherer, 1986). These results undermine models of social constructivism that lead to the expectation that there will be high variance across cultures in the underlying dynamics of anger.

Importantly, predictions \#3 and \#6 - which show that anger is more likely to be elicited when an offender intends to impose a cost specifically on the angry individual - appear contrary to what one would predict from theories of anger that suggest that the processes of anger have their origins in social consensus, social learning, cultural inheritance, or norm enforcement. This is because angry individuals and third parties appear to have opposite responses to an offender targeting the victim (i.e. the angry person) in particular. On one hand, offenders who target at random are considered more worthy of punishment by third parties (Miller, Rossi, \& Simpson, 1991), a pattern with real world effects, e.g. criminals who randomly target their victims are more likely to be prosecuted, more likely to be convicted, and more likely to be executed for their crimes (Dawson, 2004; Hessick, 2007; Simon, 1996). On the other hand, despite this widespread norm of justice, individuals on whom costs are imposed are less likely to be angered if the offender targeted them at random, as shown in Experiment Sets B and D and as predicted by the recalibrational theory. In short, this particular aspect of anger - being less angry

\footnotetext{
${ }^{6}$ The extent to which another individual benefits from your presence and your cooperation is a component of cooperative value and association value (see Petersen et al., 2012; Sell et al., 2009; Tooby \& Cosmides, 1996) and thus contributes to bargaining power. As such, an individual who underestimates the extent to which they depend on another can expect to trigger anger in that individual, which functions to recalibrate their estimates of cooperative value or association value and thus increase WTR.

7 Indeed, we designed different vignettes for the Shuar precisely because different resources are valued across cultures. While we expect cultural calibration of costs and benefits, the universal functional grammar is predicted (by the recalibrational theory) to be the same, and the experiments presented here offer evidence to that effect.
} 
when one is targeted at random - is unlikely to be due to a societal norm because the norm is the opposite of this.

\subsection{Anger and other emotions}

Anger is not the only emotion that has been posited to calibrate and respond to welfare tradeoff ratios (see Sznycer, Cosmides, \& Tooby, 2017; Tooby \& Cosmides, 2008, for gratitude, compassion, guilt, shame, and pride, for example). Maintaining optimal concern for others' welfare would have been a powerful selection pressure, and there are likely many evolved mechanisms that govern how humans process information and behave in welfare tradeoff transactions. For example, gratitude is the complementary emotion to anger: When others treat one unexpectedly well, gratitude upregulates the welfare tradeoff ratio to reinforce a higher level of mutual cooperation (Lim, 2012; Tooby \& Cosmides, 2008). Similarly, reverse engineering the features of guilt suggests that it is an adaptation for recalibrating one's own welfare tradeoff ratio toward another (Tooby \& Cosmides, 2008) when one imposes undue costs on a valued other. This will sometimes co-occur with another's anger, e.g. you forget to pick up a friend at the airport. Guilt can function to recalibrate WTRs in the absence of another's anger though, e.g. you leave your baby in the hot car because you are busy talking on your phone, then return to a crying red-faced baby who is overjoyed to see their rescuer with no knowledge that it was - in fact - your fault that they are suffering.

Shame, a related emotion, may also co-occur with another's anger. Shame orchestrates cognition and behavior to minimize (i) the likelihood that negative information about an individual (e.g. stinginess, incompetence) reaches other people's minds, and (ii) the extent of any ensuing decrease in others' WTRs with respect to the individual (Sznycer, 2010; see also Fessler, 1999). Shame defends the individual against information-triggered devaluation (e.g. by motivating the destruction of incriminating evidence) whether others are seen as deserving higher WTRs or not (whether guilt is also mobilized or not). Recent findings indicate a close match between the intensity of shame in the discredited individual and the adverse reaction of the audience (Sznycer, De Smet et al., 2016), suggesting that these emotions are informed by the same underlying welfare-tradeoff architecture (see also Sznycer, AlShawaf et al., 2017; Sznycer et al., 2015; Sznycer, Tooby et al. 2016).

\subsection{Conclusion}

In this paper, six predictions were derived from the recalibrational theory's account of how the infliction of costs can trigger anger. These predictions were confirmed and replicated across six diverse cultures ranging from very peaceful (Australians) to one of the more violent (the Shuar of Ecuador). In all cases, the conceptual grammar of anger appeared to be the same: cost inflictions trigger anger when they indicate welfare tradeoff ratios that are too low. Furthermore, in all tested cultures, when confronted with anger, individuals deployed arguments designed to indicate that their WTR toward the angry individual was high, and shunned arguments that indicated that their WTR was low. Future research will determine whether other triggers of anger can be equally explained and predicted from this model.

In conclusion, there are good theoretical reasons to believe that evolution by natural selection provides the underlying functional logic that explains how anger works. The exquisitely detailed, functionally interlocking characteristics of the species-typical physiological/anatomical architecture of anger - the universal facial expression of anger, the coordinated changes in physiological and perceptual systems - appear to be complemented by a complex computational architecture organized to perceive cues of
WTRs, calculate intentions with respect to welfare outcomes, compute levels of entitlement, deploy arguments, trigger threats and acts of aggression, tactically withdraw cooperation, and otherwise regulate psychological variables and behavioral outputs in ways that led to self-beneficial bargaining resolutions of conflicts. This complexity - if it is indeed the result of natural selection - can be mapped and understood if we know what evolutionary function it served. The recalibrational theory offers one parsimonious functional explanation that unites these diverse phenomena into a unified system.

\section{Acknowledgements}

We thank June Betancourt, Howard Waldow, the members of the Center for Evolutionary Psychology, especially Dr. Andrew Delton and Dr. Elsa Ermer. We also thank Dr. Silviu Nisu, Gabriella Foldenyi, Dr. Simon Little, Dr. Michael Townsley, Dr. Poesis Petrescu, Dr. Ovidiu Gavrilovici, Dr. Roxana Toma and Dr. Mihaela Muresan for their valuable insights and assistance. Financial support for this project was provided by an NIH Director's Pioneer Award to Leda Cosmides and a grant from the John Templeton Foundation to John Tooby and Leda Cosmides. The opinions expressed in this publication are those of the authors and do not necessarily reflect the views of the NIH or the JTF.

\section{Appendix A. Supplementary materials}

Supplementary data associated with this article can be found, in the online version, at http://dx.doi.org/10.1016/j.cognition.2017. 06.002 .

\section{References}

Alcock, J. (2005). Animal behavior: An evolutionary approach (8th ed.). Sunderland MA: Sinauer.

Alonso-Arbiol, I., van de Vijver, F. J. R., Fernandez, I., Paez, D., Campos, M., \& Carrera, P. (2011). Implicit theories about interrelations of anger components in 25 countries. Emotion, 11(1), 1-11. http://dx.doi.org/10.1037/a0020295.

Averill, J. (1982). Anger and aggression: An essay on emotion. New York: SpringerVerlag.

Averill, J. (1983). Studies on anger and aggression: Implications for theories of emotion. American Psychologist, 38(11), 1145-1160.

Banse, R., \& Scherer, K. R. (1996). Acoustic profiles in vocal emotion expression. Journal of Personality and Social Psychology, 70(3), 614-636.

Barrett, L. F. (2017). How emotions are made: The secret life of the brain. Pan Macmillan.

Barrett, L. F., \& Russell, J. A. (2014). The psychological construction of emotion. Guilford Publications.

Berkowitz, L. (1988). Frustrations, appraisals, and aversively stimulated aggression. Aggressive Behavior, 14(1), 3-11.

Berkowitz, L. (1990). On the formation and regulation of anger and aggression: A cognitive-neoassociationistic analysis. American Psychologist, 45(4), 494.

Berkowitz, L., \& Harmon-Jones, E. (2004). Toward an understanding of the determinants of anger. Emotion, 4(2), 107-130.

Berkowitz, L., \& Walster, E. (1976). Advances in experimental social psychology (Vol 9) New York: Academic Press.

Carver, C., \& Harmon-Jones, E. (2009). Anger is an approach-related affect: Evidence and implications. Psychological Bulletin, 135(2), 183-204.

Daly, M., \& Wilson, M. (1988). Homicide. New York: de Gruyter.

Dawson, M. (2004). Rethinking the boundaries of intimacy at the end of the century: The role of victim-defendant relationship in criminal justice decisionmaking over time. Law \& Society Review, 38(1), 105-138.

Delton, A. W. \& Robertson, T. E. (2016). How the mind makes welfare tradeoffs: Evolution, computation, and emotion. Current Opinion in Psychology, 7, 12-16.

Delton, A., \& Sell, A. (2014). The co-evolution of concepts and motivation. Current Directions in Psychological Science, 23(2), 115-120.

Dollard, J., Doob, L. W., Miller, N. E., Mowrer, O. H., \& Sears, R. R. (1939). Frustration and aggression. New Haven, CT: Yale University Press.

Donnerstein, E., \& Hatfield, E. (1982). Aggression and Inequity. In J. Greenberg \& R Cohen (Eds.), Equity and justice in social behavior. New York: Academic Press.

Ekman, P. (1973). Cross-cultural studies of facial expression. In P. Ekman (Ed.), Darwin and facial expression: A century of research in review (pp. 169-222). New York: Academic Press.

Enquist, M., Leimar, O., Ljungberg, T., Mallner, Y., \& Segerdahl, N. (1990). A test of the sequential assessment game: Fighting in the cichlid fish Nannacara anomala. Animal Behavior, 40, 1-14. 
Epstein, S., \& Taylor, S. P. (1967). Instigation to aggression as a function of degree of defeat and perceived aggressive intent of the opponent. Journal of Personality, 35, 265-289.

Fehr, E., \& Gaechter, S. (2000). Cooperation and punishment in public goods experiments. The American Economic Review, 90(4), 980-994.

Feldmann-Wustefeld, T., Schmidt-Daffy, M., \& Schubo, A. (2011). Neural evidence for the threat detection advantage: Differential attention allocation to angry and happy faces. Psychophysiology, 48(5), 697-707.

Felson, R. (1982). Impression management and the escalation of aggression and violence. Social Psychology Quarterly, 45(4), 245-254.

Fessler, D. M. (2010). Madmen: An evolutionary perspective on anger and men's violent responses to transgression. In International handbook of anger (pp. 361-381). New York: Springer.

Fessler, D. M. T. (1999). Toward an understanding of the universality of second order emotions. In A. L. Hinton (Ed.), Beyond nature or nurture: Biocultural approaches to the emotions (pp. 75-116). New York: Cambridge University Press.

Forguson, L. (1989). Common sense. London: Routledge.

Fox, E., Lester, V., Russo, R., Bowles, R. J., Pichler, A., \& Dutton, K. (2000). Facial expressions of emotion: Are angry faces detected more efficiently? Cognition and Emotion, 14(1), 61-92. http://dx.doi.org/10.1080/026999300378996.

Frank, R. H. (1988). Passions within reason: The strategic role of the emotions. WW Norton \& Co.

Frantz, C. M., \& Bennigson, C. (2005). Better late than early: The influence of timing on apology effectiveness. Journal of Experimental Social Psychology, 41(2), 201-207.

Galati, D., Sini, B., Schmidt, S., \& Tinti, C. (2003). Spontaneous facial expressions in congenitally blind and sighted children aged 8-11. Journal of Visual Impairment E Blindness, 97(7), 418-428.

Hamilton, W. D. (1964). The genetical evolution of social behavior. Journal of Theoretical Biology, 7, 1-52.

Hammerstein, P., \& Parker, G. A. (1982). The asymmetric war of attrition. Journal of Theoretical Biology, 96, 647-682.

Hansen, A. J. (1986). Fighting behavior in bald eagles: A test of game theory. Ecology, 67, 787.

Harris, M. B. (1993). How provoking: What makes men and women angry? Aggressive Behavior, 19(3), 199-211.

Hess, N., Helfrecht, C., Hagen, E., Sell, A., \& Hewlett, B. (2010). Interpersona aggression among Aka hunter-gatherers of the Central African Republic: Assessing the effects of sex, strength, and anger. Human Nature, 21, 330-354.

Hessick, C. B. (2007). Violence between lovers, strangers and friends. Washington Law Review, 85, 344-402.

Hirshleifer, J. (1984). On the emotions as guarantors of threats and promises. UCLA Department of Economics working paper no. 337.

Hull, C. L. (1943). Principles of behavior: An introduction to behavior theory. Oxford, England: Appleton-Century.

Huntingford, F. A., \& Turner, A. K. (1987). Animal conflict. New York: Chapman \& Hall.

Jandial, R., Hughes, S. A., Aryan, H. E., Marshall, L. F., \& Levy, M. L. (2004). The science of shrinking human heads: Tribal warfare and revenge among the South American Jivaro-Shuar. Neurosurgery, 55(5), 1215-1221.

Kaufmann, H. (1970). Aggression and altruism. New York: Holt, Rinehart \& Winston.

Kirkpatrick, M., Delton, A. W., Robertson, T. E., \& de Wit, H. (2015). Prosocia effects of MDMA: A measure of generosity. Journal of Psychopharmacology, 29, 661-668.

Komorita, S., Parks, C., \& Hulbert, T. (1992). Reciprocity and the induction of cooperation in social dilemmas. Journal of Personality and Social Psychology, 62 (4), 607-617.

Kragel, P. A., \& LaBar, K. S. (2016). Decoding the nature of emotion in the brain. Trends in Cognitive Sciences, 20(6), 444-455. http://dx.doi.org/10.1016/j. tics.2016.03.011.

Lanzetta, J., \& Englis, B. (1989). Expectations of cooperation and competition and their effects on observers' vicarious emotional responses. Journal of Personality E' Social Psychology, 56, 543-544.

Lazarus, R. (1991). Emotion and adaptation. Oxford: Oxford University Press.

Lieberman, D., Tooby, J., \& Cosmides, L. (2007). The architecture of human kin detection. Nature, 445(7129), 727-731.

Lim, J. (2012). Welfare tradeoff ratios and emotions: Psychological foundations of human reciprocity. Santa Barbara: University of California.

Lukaszewski, A. (2013). Testing an adaptationist theory of trait covariation: Relative bargaining power as a common calibrator of an interpersonal syndrome. European Journal of Personality, 27(4), 328-345.

Madsen, E. A., Tunney, R. J., Fieldman, G., Plotkin, H. C., Dunbar, R. I. M., Richardson, J., \& McFarland, D. (2007). Kinship and altruism: A cross-cultural experimental study. British Journal of Psychology, 98(2), 339-359.

Matsumoto, D., Hee Yoo, S., Nakagawa, S. \& 37 Members of the Multinational Study of Cultural Display Rules (2008). Journal of Personality and Social Psychology, 94 (6), 925-937.

Maynard Smith, J., \& Parker, G. A. (1976). The logic of asymmetric contests. Animal Behavior, 24, 159-175.

McCullough, M. E., Kurzban, R., \& Tabak, B. A. (2013). Cognitive systems for revenge and forgiveness. Behavioral \& Brain Sciences, 36, 1-58.

Miller, J. L., Rossi, P. H., \& Simpson, J. E. (1991). Felony punishments: A factoria survey of perceived justice in criminal sentencing. Journal of Criminal Law and Criminology, 82, 396-425.

Nickel, T. (1974). The attribution of intention as a critical factor in the relation between frustration and aggression. Journal of Personality, 42, 482-492.
Nisbett, R. E., \& Cohen, D. (1996). Culture of honor: The psychology of violence in the south. Westview Press.

Ohbuchi, K., \& Kambara, T. (1985). Attacker's intent and awareness of outcome, impression management, and retaliation. Journal of Experimental Social Psychology, 21, 321-330.

Ohbuchi, K. I., Kameda, M., \& Agarie, N. (1989). Apology as aggression control: Its role in mediating appraisal of and response to harm. Journal of Personality and Social Psychology, 56(2), 219.

Öhman, A., Lundqvist, D., \& Esteves, F. (2001). The face in the crowd revisited: A threat advantage with schematic stimuli. Journal of Personality and Social Psychology, 80(3), 381-396.

O'Leary, M., \& Dengerink, H. (1973). Aggression as a function of the intensity and pattern of attack. Journal of Research in Personality, 7(1), 61-70.

Patton, J. Q. (2005). Meat sharing for coalitional support. Evolution and Human Behavior, 26, 137-157.

Petersen, M. B., Sznycer, D., Sell, A., Cosmides, L. \& Tooby, J. (2013). The ancestral logic of politics: Upper-body strength regulates men's assertion of self-interest over economic redistribution. Psychological Science, 24, 1098-1103.

Petersen, M. B., Sell, A. Tooby, J., \& Cosmides, L. (2012). To punish or repair? Evolutionary psychology and lay intuitions about modern criminal justice. Evolution and Human Behavior, 33(6), 682-695.

Petersen, M. B., Sell, A., Tooby, J., \& Cosmides, L. (2010). Evolutionary psychology and criminal justice: A recalibrational theory of punishment and reconciliation. In H. Høgh-Olesen (Ed.), Human morality and sociality. Palgrave Macmillan.

Pietraszewski, D., \& Shaw, A. (2015). Not by strength alone: Children's expectations follow the logic of the asymmetric war of attrition. Human Nature, 26(1), 44-72.

Poole, J. (1989). Announcing intent: The aggressive state of musth in African elephants. Animal Behavior, 37, 140-152.

Potegal, M., Stemmler, G., \& Spielberger, C. (2010). International handbook of anger. Springer.

Preston, K., \& Kimberley, S. (1987). What's the worst thing...? Gender-directed insults. Sex Roles, 17(3), 209-219.

Scherer, K. R., \& Brosch, T. (2009). Culture-specific appraisal biases contribute to emotion dispositions. European Journal of Personality, 23(3), 265-288.

Scherer, K. R., \& Wallbott, H. G. (1994). Evidence for universality and cultural variation of differential emotion response patterning. Journal of Personality and Social Psychology, 66, 310-328.

Sell, A. (2006). Regulating welfare tradeoff ratios: Three tests of an evolutionarycomputational model of human anger. Doctoral Dissertation. University of California, Santa Barbara.

Sell, A. (2011b). The recalibrational theory and violent anger. Aggression and violent behavior, 16, 381-389.

Sell, A., Bryant, G., Cosmides, L., Tooby, J., Sznycer, D., von Rueden, C.,... Gurven, M. (2010). Adaptations in humans for assessing physical strength and fighting ability from the voice. Proceedings of the Royal Society, 277, 3509-3518.

Sell, A., Cosmides, L., \& Tooby, J. (2014). The human anger face evolved to enhance cues of strength. Evolution and Human Behavior, 35(5), 425-429.

Sell, A., Cosmides, L., Tooby, J., Sznycer, D., von Rueden, C., \& Gurven, M. (2009). Human adaptations for the visual assessment of strength and fighting ability from the body and face. Proceedings of the Royal Society B, 276, 575-584.

Sell, A., Eisner, M., \& Ribeaud, D. (2016). Bargaining power and adolescent aggression: The role of fighting ability, coalitional strength, and mate value. Evolution and Human Behavior, 2, 105-116.

Sell, A. (2011a). Applying adaptationism to human anger: The recalibrational theory. In P. R. Shaver \& M. Mikulincer (Eds.), Human aggression and violence. Washington, DC: American Psychological Association.

Sell, A., Tooby, J., \& Cosmides, L. (2009). Formidability and the logic of human anger. Proceedings of the National Academy of Science, 106(35), 15073-15078.

Simon, L. M. J. (1996). Legal treatment of the victim-offender relationship in crimes of violence. Journal of Interpersonal Violence, 11(1), 94-106.

Smith, C. A., \& Ellsworth, P. C. (1985). Patterns of cognitive appraisal in emotion. Journal of Personality and Social Psychology, 48, 813-838.

Smith, H. J., \& Pettigrew, T. F. (2015). Advances in relative deprivation theory and research. Social Justice Research, 28(1), 1-6.

Steel, D. (1999). Trade goods and Jivaro warfare: The Shuar 1850-1957, and the Achuar, 1940-1978. Ethnohistory, 46(4), 745-776.

Stenberg, C. R., Campos, J. J., \& Emde, R. N. (1983). The facial expression of anger in seven-month-old infants. Child Development, 54(1), 178-184.

Sugiyama, L. S. (2005). Physical attractiveness: An adaptationist perspective. In D. Buss (Ed.) The handbook of evolutionary psychology.

Sznycer, D. (2010). Cognitive adaptations for calibrating welfare tradeoff motivations, with special reference to the emotion of shame Doctoral dissertation. Santa Barbara: University of California.

Sznycer, D., Al-Shawaf, L., Bereby-Meyer, Y., Curry, O. S., De Smet, D., Ermer, E., ... Tooby, J. (2017). Cross-cultural regularities in the cognitive architecture of pride. Proceedings of the National Academy of Sciences, 114(8), 1874-1879.

Sznycer, D., Cosmides, L., \& Tooby, J. (2017). Adaptationism carves emotions at their functional joints. Psychological Inquiry, 28(1), 56-62.

Sznycer, D., De Smet, D., Billingsley, J., \& Lieberman, D. (2016). Coresidence duration and cues of maternal investment regulate sibling altruism across cultures. Journal of Personality and Social Psychology, 111(2), 159-177.

Sznycer, D., Schniter, E., Tooby, J., \& Cosmides, L. (2015). Regulatory adaptations for delivering information: The case of confession. Evolution and Human Behavior, $36,44-51$. 
Sznycer, D., Takemura, K., Delton, A. W., Sato, K., Robertson, T., Cosmides, L., \& Tooby, J. (2012). Cross-cultural differences and similarities in proneness to shame: An adaptationist and ecological approach. Evolutionary Psychology, 10 (2), 352-370.

Sznycer, D., Tooby, J. Cosmides, L. Porat, R. Shalvi, S., \& Halperin, E. (2016). Shame closely tracks the threat of devaluation by others, even across cultures. Proceedings of the National Academy of Sciences, 113(10), 2625-2630.

Tedeschi, J., \& Felson, R. (1994). Violence, aggression \& coercive actions. Washington, DC: American Psychological Association.

Thomsen, L., Frankenhuis, W. E., Ingold-Smith, M., \& Carey, S. (2011). Big and mighty: Preverbal infants mentally represent social dominance. Science, 331, 477-480.

Tomasello, M., Carpenter, M., Call, J., Behne, T., \& Moll, H. (2005). Understanding and sharing intentions: The origins of cultural cognition. Behavioral and Brain Sciences, 28(5), 675-691.

Tooby, J., \& Cosmides, L. (1990). The past explains the present: Emotional adaptations and the structure of ancestral environments. Ethology and Sociobiology, 11, 375-424.
Tooby, J., \& Cosmides, L. (1996). Friendship and the Banker's Paradox: Other pathways to the evolution of adaptations for altruism. Proceedings of the British Academy, 88, 119-143.

Tooby, J., \& Cosmides, L. (2008). The evolutionary psychology of the emotions and their relationship to internal regulatory variables. In M. Lewis, J. M. HavilandJones, \& L. F. Barrett (Eds.), Handbook of emotions (3rd ed.. New York, NY: Guilford Press.

Tooby, J., Cosmides, L., Sell, A., Lieberman, D., \& Sznycer, D. (2008). Internal regulatory variables and the design of human motivation: A computational and evolutionary approach. In Andrew J. Elliot (Ed.), Handbook of approach and avoidance motivation (pp. 251-271). New York, NY, US: Psychology Press.

Wallbott, H., \& Scherer, K. (1986). The antecedents of emotional experiences. In K. Scherer, H. Wallbott, \& A. Summerfield (Eds.), Experiencing emotion: A crosscultural study (pp. 69-83). Cambridge: Cambridge University Press.

Walster, E., Berscheid, E., \& Walster, G. W. (1973). New directions in equity research. Journal of Personality and Social Psychology, 25(2), 151.

Williams, K. D., Shore, W. J., \& Grahe, J. E. (1998). The silent treatment: Perceptions of its behaviors and associated feelings. Group Processes \& Intergroup Relations, 1 (2), 117-141. 